\title{
A hemolytic anti-LKE associated with a rare LKE-negative, "weak P" red blood cell phenotype: alloanti-LKE and alloanti-P recognize galactosylgloboside and monosialogalactosylgloboside (LKE) antigens
}

\author{
Laura Cooling, ${ }^{1}$ Louann R. Dake, ${ }^{1}$ Donna Haverty, ${ }^{3}$ Nancy Mullis, ${ }^{3}$ Susie Ellis, ${ }^{4}$ James Shayman, ${ }^{2}$ \\ and W. John Judd ${ }^{1}$
}

BACKGROUND: "Weak P" is a rare red blood cell (RBC) phenotype, characterized by a global decrease in $\mathrm{P}^{\mathrm{k}}$ and $\mathrm{P}$ antigens. We now describe a second weak $P$ individual who also typed LKE-negative (LKE-N) and possessed a clinically significant anti-LKE.

STUDY DESIGN AND METHODS: Patient RBCs and plasma were examined by standard serology and flow cytometry. Glycosphingolipids (GSLs) from patient, $\mathrm{P}^{\mathrm{k}}$, and LKE-strong (LKE-S) RBCs were isolated and analyzed by high-performance thin-layer chromatography (HPTLC). To confirm antibody specificity, patient serum and 30 human polyclonal controls, including alloanti-P and anti-PP ${ }_{1} \mathrm{P}^{\mathrm{k}}$, were tested against a panel of GSLs by HPTLC immunostaining.

RESULTS: The patient typed $\mathrm{P}_{1}+, \mathrm{P}_{+}$, and LKE-N and possessed a "P-like" panagglutinin. In a two-stage indirect antiglobulin test, the patient's plasma caused hemolysis of LKE-S cells but not $p, P^{k}$, or LKE-N cells. Clinically, transfusion of $\mathrm{P}+\mathrm{RBC}$ compatible by a prewarmed technique had shortened RBC survival with laboratory evidence of hemolysis. Analysis of the patient's isolated RBC GSLs showed a $30 \%$ relative decrease in $\mathrm{Gb3}\left(\mathrm{P}^{\mathrm{k}}\right)$ and $\mathrm{Gb} 4(\mathrm{P})$ and a $90 \%$ decrease in monosialogalactosylgloboside (MSGG, LKE), accompanied by increased lactosylceramide $(\mathrm{CDH})$, paragloboside, and GM3. On HPTLC immunostaining, the patient's plasma strongly bound MSSG with weak binding to galactosylgloboside (Gb5). Binding to MSGG, $\mathrm{Gb5}$, and Gb4 was also observed with some examples of alloanti-P from $\mathrm{P}^{\mathrm{k}}$ individuals, but not anti- $\mathrm{PP}_{1} \mathrm{P}^{\mathrm{k}}$, autoanti-P, or normal controls.

CONCLUSIONS: We describe the first example of a clinically significant anti-LKE in the setting of a rare weak $P$ background. Human alloanti-LKE and some alloanti-P recognized $\mathrm{Gb5}$ and MSGG.

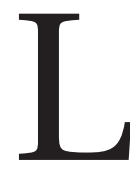

KE is a sialylated, globo-family glycosphingolipid (GSL) $)^{1,2}$ that is biosynthetically related to the $\mathrm{P}^{\mathrm{k}}$ (Gb3) and $\mathrm{P}(\mathrm{Gb} 4)$ antigens. Like $\mathrm{P}^{\mathrm{k}}$ and $\mathrm{P}$ antigens, LKE is a high-frequency antigen on human red blood cells (RBCs), with $98 \%$ to $99 \%$ of donors typing LKE-positive. ${ }^{2-7}$ LKE varies in strength between individuals, with $80 \%$ to $90 \%$ typing LKE-strong (LKE-S) and $10 \%$ to $20 \%$ individuals as LKE-weak (LKE-W). LKE-negative (LKE-N) is reported in $1 \%$ to $2 \%$ of $\mathrm{P}+$ donors, as well as rare $\mathrm{p}$ and $\mathrm{P}^{\mathrm{k}}$ individuals who are deficient in complex globo-GSLs. Interestingly, there is an apparent inverse relationship between LKE and $\mathrm{P}^{\mathrm{k}}$, with many LKE-N donors showing elevated $\mathrm{P}^{\mathrm{k}}$ expression reminiscent of a " $\mathrm{P}^{\mathrm{k}}$ variant" phenotype. ${ }^{4,7,8}$ LKE may also have interactions with other carbohydrate blood groups. In uroepithelial

ABBREVIATIONS: DSGG = disialogalactosylgloboside; GSL = glycosphingolipid; HMW = high-molecular-weight; HPTLC = high-performance thin-layer chromatography; IS = immediate spin; LKE-N = LKE-negative;

LKE-S = LKE-strong; LKE-W = LKE-weak;

MSGG = monosialogalactosylgloboside; $\mathrm{PCH}=$ paroxysmal cold hemoglobinuria; RT = room temperature; Stx = Shiga toxin.

From the ${ }^{1}$ Department of Pathology and the ${ }^{2}$ Department of Nephrology, University of Michigan, Ann Arbor, Michigan; the ${ }^{3}$ American Red Cross Blood Services, Southern Region, Atlanta, Georgia; and the ${ }^{4}$ Veteran's Administration Hospital, Augusta, Georgia.

Address reprint requests to: Laura Cooling MD, MS,

Transfusion Medicine, University of Michigan Hospitals, 1500 E. Medical Center Drive, Ann Arbor, MI 48109-0054; e-mail: lcooling@med.umich.edu.

Received for publication March 13, 2013; revision received May 17, 2014, and accepted May 28, 2014.

doi: $10.1111 /$ trf. 12772

(C) $2014 \mathrm{AABB}$

TRANSFUSION 2015;55:115-128. 
TABLE 1. Examples of anti-LKE reported in the literature

\begin{tabular}{|c|c|c|c|c|c|c|c|c|c|}
\hline \multirow[b]{2}{*}{ Case } & \multirow[b]{2}{*}{$\begin{array}{c}\text { Age } \\
\text { (years)/sex }\end{array}$} & \multirow[b]{2}{*}{ Ethnicity } & \multirow[b]{2}{*}{ Diagnosis } & \multirow[b]{2}{*}{$\begin{array}{c}\text { Prior } \\
\text { sensitization }\end{array}$} & \multicolumn{2}{|c|}{ Antibody titer } & \multirow[b]{2}{*}{$\mathrm{IAT}^{*}$} & \multirow[b]{2}{*}{ Significant } & \multirow[b]{2}{*}{ Reference } \\
\hline & & & & & $\begin{array}{l}\text { Unmodified } \\
\text { RBCs }\end{array}$ & $\begin{array}{c}\text { Enzyme } \\
\text { RBCs }\end{array}$ & & & \\
\hline 1 & 32/male & Black & Hodgkin's lymphoma & No & 256 & 512 & C3 & NR & Tippett, $1965^{5}$ \\
\hline 2 & NA/female & NA & Prenatal & Yes, $\mathrm{G}_{2} \mathrm{P}_{1} \dagger$ & 2 & 4 & C3 only & No & Bruce, $1988^{7}$ \\
\hline 3 & $32 /$ female & Danish & Prenatal & Yes, $\mathrm{G}_{2} \mathrm{P}_{1} \ddagger$ & 4 & 16, IAT & $\lg G \ddagger$ & No & Moller, $1988^{6}$ \\
\hline 4 & $\mathrm{NA} / \mathrm{male}$ & Algerian & Cardiac & No & NR & NR & NR & NR & Race, $1965^{10}$ \\
\hline 5 & NA/female & Turkish & NR & NR & "Weak" & NR & NR & NR & Race, $1965^{10}$ \\
\hline 6 & $58 /$ male & White & Large B-cell lymphoma & Unknown§ & ND & 256 & C3 & Yes & This study \\
\hline
\end{tabular}

tissues, LKE can be weakened in the presence of secretor. ${ }^{9}$ Serologic studies with rare human anti-LKE also suggest an association between LKE-W, $\mathrm{A}_{1}$, and $\mathrm{P}_{2}$ phenotypes. ${ }^{5,6}$

Although $1 \%$ to $2 \%$ of the population types as LKE-N, alloantibodies to LKE are actually quite rare, with only five cases mentioned in the literature. ${ }^{5-7,10}$ All acted as direct panagglutinins, with most capable of fixing complement in vitro (Table 1). The first example was found in an untransfused man with Hodgkin's disease. ${ }^{5}$ Two examples were identified in prenatal samples ${ }^{6,7}$ and an additional two were identified in routine testing. ${ }^{10}$ Based on available literature, anti-LKE appears to be clinically insignificant.

We now report a sixth example of an alloanti-LKE. Unlike prior cases, this patient had clinical evidence of shortened RBC survival and hemolysis after repeated transfusions with LKE+ blood that was compatible in prewarmed testing. In addition, we show evidence that the LKE-N phenotype arose from a "weak P" RBC phenotype, ${ }^{11}$ with weakened expression of all globo-GSLs. This is the second case of a weak $\mathrm{P}$ and the first associated with a LKE-N phenotype. Finally, we provide the first direct evidence of human alloanti-LKE binding to monosialogalactosylgloboside (MSGG), the putative LKE antigen.

\section{CASE REPORT}

The patient was a 58-year-old white man with a history of gastroesophageal reflux disease, hypertension, Type II diabetes, atrial fibrillation, congestive heart failure with an ejection fraction of $25 \%$ to $30 \%$, chronic microcytic anemia, and a 1-year history of a nonpainful right groin mass. He was initially seen in a local primary care facility, where he was transfused with 2 RBC units for a hemoglobin $(\mathrm{Hb})$ of $9.7 \mathrm{~g} / \mathrm{dL}$. He was referred to a local hospital 1 week later for further evaluation of his anemia. At that time, his $\mathrm{Hb}$ was $7.0 \mathrm{~g} / \mathrm{dL}$ with a weakly positive direct antiglobulin test (DAT; 1+, anti-C3 only). In addition, a cold agglutinin with "P-like" specificity was identified in his plasma. He received no additional transfusions due to difficulty finding compatible blood. He was subsequently transferred to a large regional hospital for management of his anemia and investigation of his left groin mass.

Upon admission to Hospital 2, the patient was afebrile, tachycardic (pulse 104) with a $5 \times 3-\mathrm{cm}$ firm, nontender, left groin mass. A complete blood count was significant for a hypochromic, microcytic anemia ( $\mathrm{Hb}$ $7.1 \mathrm{~g} / \mathrm{dL}, \mathrm{MCV}$ 79, MCH 25.9), mild leukocytosis $\left(17.6 \times 10^{9} / \mathrm{L}\right)$, and thrombocytosis $\left(614 \times 10^{11} / \mathrm{L}\right)$. Chemistry studies showed a normal serum iron, normal bilirubin, mildly depressed transferrin, and elevated ferritin $(11,600 \mathrm{ng} / \mathrm{mL}$; normal range, $12-300 \mathrm{ng} / \mathrm{mL})$ and haptoglobin (375 mg/dL; normal range, $23-200 \mathrm{mg} / \mathrm{dL}$ ). There was no evidence of gastrointestinal bleeding by endoscopy and stool guaiac tests. A CT scan revealed splenomegaly with periaortic, iliac, and inguinal lymphadenopathy: There was no evidence of retroperitoneal or intrabdominal hemorrhage.

On Hospital Day 2, the patient became hypotensive and was transfused with 2 units of group O RBCs. Both units were strongly incompatible $(3+)$ by immediate-spin (IS) cross-match and weakly $( \pm)$ reactive in polyethylene glycol (PEG) indirect antiglobulin tests (IATs), but were compatible using a prewarmed technique. ${ }^{12,13}$ Both units were transfused without incident but failed to elicit the expected increase in $\mathrm{Hb}$, with a posttransfusion $\mathrm{Hb}$ of only 7.7 g/dL (Fig. 1).

On Day 5, the patient received an additional 2 RBC units before a scheduled lymph node biopsy. As before, units were cross-matched by a prewarmed technique. The patient was medicated before transfusion with acetaminophen, diphenhydramine, and dexamethasone. The patient tolerated transfusion with an appropriate $2 \mathrm{~g} / \mathrm{dL}$ increase in $\mathrm{Hb}$; however, his $\mathrm{Hb}$ quickly decreased to pretransfusion levels within 24 hours. Over the next 6 days, the patient was transfused an additional 5 units with no sustained increase in $\mathrm{Hb}$ (Fig. 1A). Transfusions were accompanied by increased lactate dehydrogenase (LDH), total bilirubin, and decreasing haptoglobin (Fig. 1B). By Day 11 , the patient was noted to be jaundiced with a total 


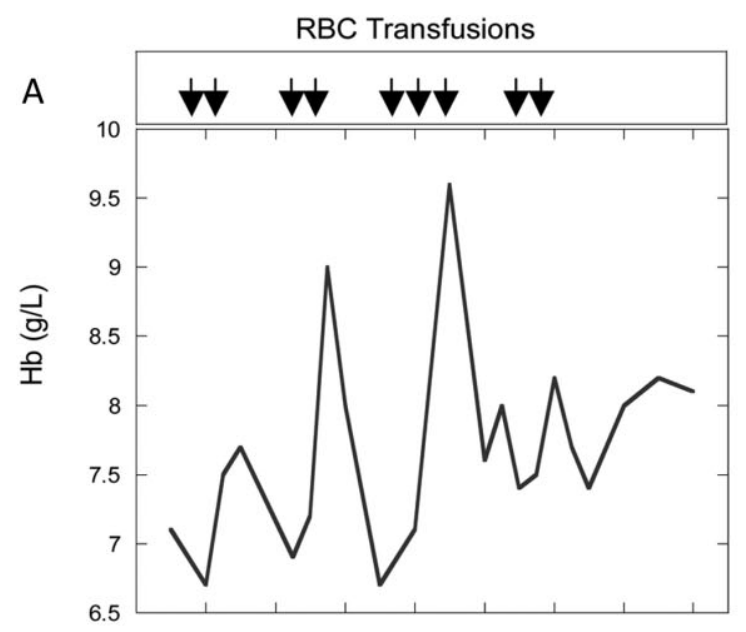

B
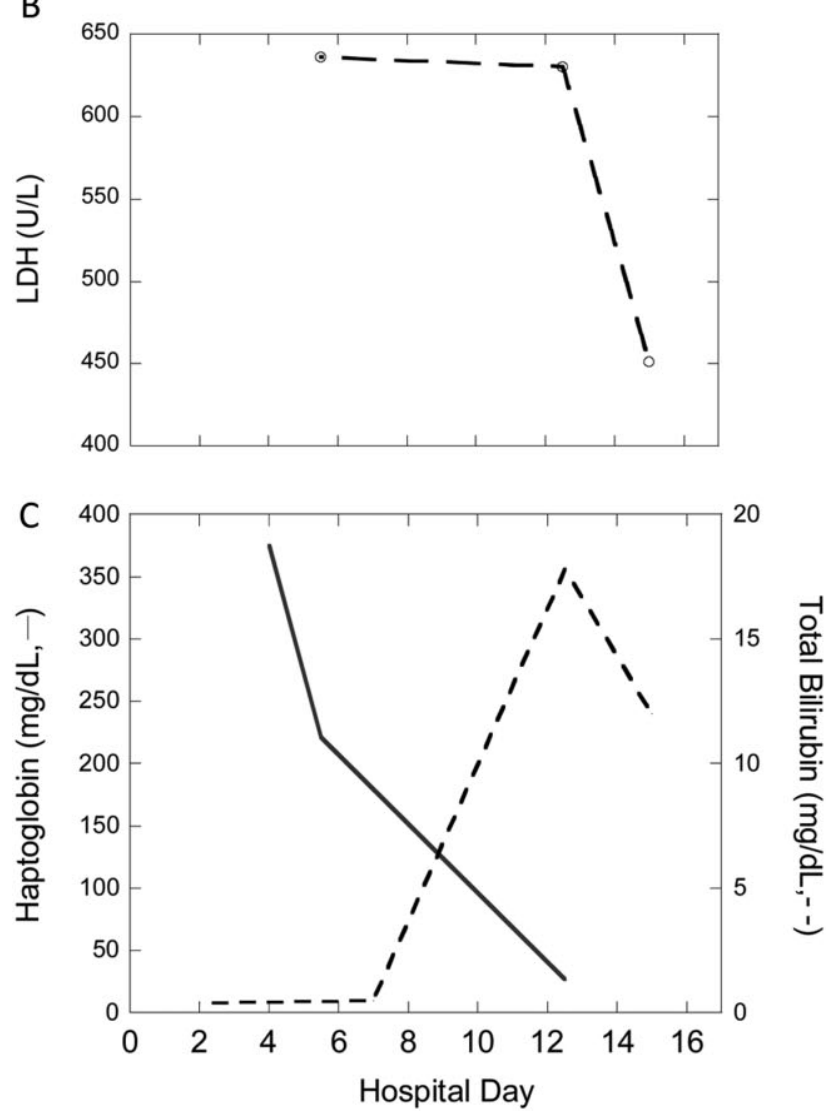

Fig. 1. Patient clinical course following transfusion of $P+R B C$ units compatible by a prewarmed cross-match technique over the course of hospitalization at Hospital 2. (A) Patient's Hb, (B) LDH, and (C) haptoglobin (-) and total bilirubin (- -). Arrows indicate transfusion of group $\mathrm{O}_{+}$, leukoreduced irradiated RBC units.

bilirubin of $17.9 \mathrm{mg} / \mathrm{dL}$ ( $64 \%$ direct bilirubin), elevated reticulocytes (4.9\%), and low haptoglobin. In addition, his DAT was 2+ (anti-C3) with spherocytes and rouleaux noted on a peripheral blood smear.
Given laboratory evidence of a delayed hemolytic transfusion reaction, it was decided to forego any further transfusions unless the patient became symptomatic. A histologic examination of his left inguinal lymph node revealed a large B-cell lymphoma. On Day 15, the patient was treated with one course of rituximab, cyclophosphamide, and vincristine. He was discharged on Day 17 to the care of a local oncologist. The patient died 3 months after discharge of unknown causes.

\section{MATERIALS AND METHODS}

\section{Immunologic reagents}

Monoclonal antibodies (MoAbs) against P/Gb4 (MoAb MC631), ${ }^{14}$ LKE/MSGG (MoAb MC18-70), ${ }^{1}$ and lactosamine (MoAb FeA5) ${ }^{15}$ were obtained from the Developmental Studies Hybridoma Bank held at the University of Iowa (Iowa City, IA). Shiga toxin (Stx) and anti-Stx IgG were purchased from Toxin Technology (Sarasota, FL). Stx was labeled with fluorescein isothiocyanate (FITC) as described. ${ }^{4}$ The resulting Stx-free dialysate was retained as a negative control. SC802, a recombinant P-fimbriated Escherichia coli strain, and HB101, a nonfimbriated E. coli control, were a gift from S. Clegg (Department of Microbiology, University of Iowa). ${ }^{16}$ Biotinylated anti-mouse (IgG, IgM) and anti-human (IgG, IgM) antibodies, streptavidin-alkaline phosphatase, and alkaline phosphatase substrate were purchased from Vector Laboratories (Burlingame, CA). FITC-labeled anti-mouse antibodies (IgG, IgM) and Clostridium perfringens Type IV neuraminidase were purchased from Sigma (St Louis, MO). The immunologic reactivity and structure of various GSL antigens is shown in Table 2.

Rare human RBCs and antibodies were obtained via the SCARF International Exchange Program ${ }^{17}$ and the University of Michigan Immunohematology Reference Laboratory. $P_{1}{ }^{k}$ cells for GSL extraction were a gift from R. Thompson (University of Minnesota). Anti-mouse IgG gel cards were a gift from H. Malyska (Micro Typing Systems, Pompano Beach, FL). All other serologic reagents were from Ortho Clinical Diagnostics (Raritan, NJ) or ImmucorGamma (Norcross, GA) and used according the manufacturers' instructions.

\section{RBC studies}

LKE typing was performed with MoAb MC813-70 as described..$^{4,18}$ Samples agglutinating at IS were typed as LKE-S. Negative samples were tested by the IAT using antimouse IgG. Samples negative at IS, but positive by the IAT, were typed as LKE-W. Samples failing to agglutinate by IS and IAT were typed as LKE-N. LKE-N samples were tested for P antigen with MoAb MC631. ${ }^{4,14}$

Other serologic tests were performed as described previously. ${ }^{12,13}$ Reactions were graded and scored 


\begin{tabular}{|c|c|c|c|}
\hline Name/family & Specificity & Structure & Reagent* $^{*}$ \\
\hline $\mathrm{CMH}$ & Glucosylceramide & Glc $\beta 1-1$ Cer & \\
\hline $\mathrm{CDH}$ & Lactosylceramide & Gal $\beta 1-4 G l c \beta 1-1$ Cer & \\
\hline GM3 & Gd† & NeuAc $\alpha 2-3 G a l \beta 1-4 G \mid c \beta 1-1$ Cer & \\
\hline \multicolumn{4}{|l|}{ Globo-series } \\
\hline Gb3 & $\mathrm{P}^{\mathrm{k}}, \mathrm{CD} 77$ & Gal $\alpha 1-4 \mathrm{Gal} \beta 1-4 \mathrm{Glc} \beta 1-1 \mathrm{Cer}$ & Stx \\
\hline Gb4 & $\mathrm{P}$ & GalNAc $\beta 1-3 G a l \alpha 1-4$ Gal $\beta 1-4 G l c \beta 1-1$ Cer & MC631 \\
\hline Gb5 & SSEA-3 & Gal $\beta 1-3 G a l N A c \beta 1-3 G a l \alpha 1-4$ Gal $\beta 1-4 G \mid c \beta 1-1$ Cer & MC631 \\
\hline Forssman & & GalNAc $\alpha 1-3 G a I N A c \beta 1-3 G a l \alpha 1-4 G a \mid \beta 1-4 G l c \beta 1-1$ Cer & \\
\hline Globo-H & Type $4 \mathrm{H}$ & Fuc $\alpha 1-2 \mathrm{Gal} \beta 1-3 \mathrm{GalNAc} \beta 1-3 \mathrm{Gal} \alpha 1-4 \mathrm{Gal} \beta 1-4 \mathrm{Glc} \beta 1-1 \mathrm{Cer}$ & MBr1 \\
\hline MSGG & LKE, SSEA-4 & NeuAc $\alpha 2-3 G$ al $\beta 1-3 G$ GalNAc $\beta 1-3 G a l \alpha 1-4 G a l \beta 1-4 G \mid c \beta 1-1$ Cer & MC813-70 \\
\hline DSGG & & $\begin{array}{l}\text { NeuAco2-3Gal } \beta 1-3 G \text { GalNAc } \beta 1-3 G a l \alpha 1-4 G a l \beta 1-4 G \mid c \beta 1-1 \text { Cer } \\
\text { NeuAc } \alpha 2-6^{\prime}\end{array}$ & $\begin{array}{l}\mathrm{nm} / \mathrm{MC} 631 \\
5 \mathrm{~F} 3\end{array}$ \\
\hline \multicolumn{4}{|c|}{ 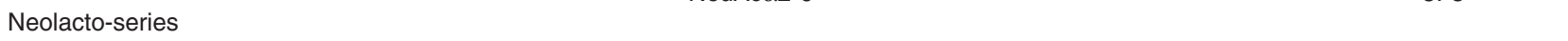 } \\
\hline $\mathrm{nLc4}$ & Paragloboside & Gal $\beta 1-4 G I c N A c \beta 1-3 G a l \beta 1-4 G l c \beta 1-1$ Cer & FeA5 \\
\hline$\alpha G a l-n L c 4$ & $\mathrm{P}_{1}$ antigen & Gal $\alpha 1-4 G a l \beta 1-4 G|c N A c \beta 1-3 G a l \beta 1-4 G| c \beta 1-1 C e r$ & Stx \\
\hline$\beta$ GalNAc-nLc4 & PX2, P-like & GalNAc $\beta 1-3 G a l \beta 1-4 G \mid c N A c \beta 1-3 G a l \beta 1-4 G l c \beta 1-1 C e r$ & \\
\hline snLc4 & Sialylparagloboside & NeuAc $\alpha 2-3 G a l \beta 1-4 G I c N A c \beta 1-3 G a l \beta 1-4 G l c \beta 1-1 C e r$ & $\mathrm{~nm} / \mathrm{FeA} 5 \ddagger$ \\
\hline snLc6 & & NeuAc $\alpha 2-3 G a l \beta 1-4$ GIcNAc $\beta 1-3 G a l \beta 1-4 G|c N A c \beta 1-3 G a l \beta 1-4 G| c \beta 1-1$ Cer & $\mathrm{nm} / \mathrm{FeA} 5 \ddagger$ \\
\hline \multicolumn{4}{|c|}{ 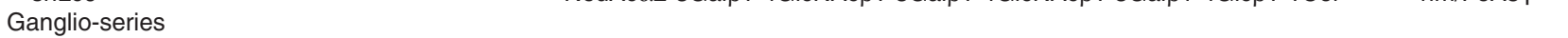 } \\
\hline GM1 & & 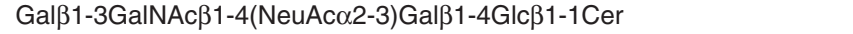 & Cholera toxin \\
\hline GD1a & & 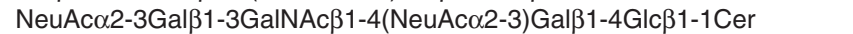 & \\
\hline GD1b & & Gal $\beta 1-3 G a l N A c \beta 1-4(N e u A c \alpha 2-8$ NeuAc $\alpha 2-3)$ Gal $\beta 1-4 G l c \beta 1-1$ Cer & \\
\hline \multicolumn{4}{|c|}{$\begin{array}{l}\text { * MoAbs and lectins against GSL antigens. } \\
\text { † GM3 is recognized by Gd (glycolipid-dependent) cold agglutinins. } \\
\text { ₹ Nm/FeA5, reactive after in situ digestion of gangliosides with neuraminidase, followed by staining with MoAb FeA5. } \\
\text { Cer = ceramide; Fuc = fucose; Gal = galactose; GalNAc = N-acetylgalactosamine; Glc = glucose; GlcNAc = N-acetylglucosamine; Gd = glyco- } \\
\text { lipid-dependent cold agglutinin; NeuAc = N-acetylneuraminic acid; } \mathrm{nm}=\text { in situ neuraminidase digestion; SSEA = stage-specific embryonic } \\
\text { antigen. }\end{array}$} \\
\hline
\end{tabular}

according to the method described by Marsh. ${ }^{19}$ Bacterial hemagglutination assays using P-fimbriated E. coli were performed on buffered gel cards (Ortho) as previously described..$^{20}$

\section{Flow cytometry}

Washed, ficin-treated RBCs were stained with MoAbs or FITC-labeled Stx and analyzed by one-color flow cytometry (FACScan, Becton Dickinson, Hialeah, FL) as described. ${ }^{4}$ All samples were stained in duplicate and recorded as the mean percent positive cells and mean channel fluorescence intensity (MFI). ${ }^{4}$

\section{High-performance thin-layer chromatography}

RBC GSLs were isolated by a modified Leeden and Yu method as previously described., ${ }^{48,21}$ High-performance thin-layer chromatography (HPTLC) was performed using either glass or aluminum-backed HPTLC plates (E. Merck, Darmstadt, Germany).22,23 For neutral GSL analysis, HPTLC plates were developed in standard neutral solvent (C-M-W 65:25:4, vol/vol). Gangliosides were developed in $\mathrm{C}-\mathrm{M}-0.02 \%$ aqueous $\mathrm{CaCl}_{2}$. GSLs were visualized by chemical staining (diphenylamine, charring) or HPTLC immunostaining. ${ }^{22,23}$ GSLs were characterized by relative mobility $\left(\mathrm{R}_{\mathrm{f}}\right)$ and relative intensity by scanning densitometry (Quantiscan, Biosoft, Ferguson, MO). GSL standards were purchased from Sigma or Matreya (Pleasant Gap, PA). Paragloboside (nLc4), Gb5, MSGG, neutrophil, and ACHN GSLs were isolated previously. ${ }^{23}$

\section{HPTLC immunostaining}

For immunostaining, HPTLC plates were coated in $0.2 \%$ poly(iso)butyl-methacrylate in hexane for 1 minute and dried for at least 1 hour at room temperature (RT). ${ }^{18,23}$ For staining with human antisera, plates were initially blocked for 1.5 hours with phosphate-buffered saline (PBS) $-3 \%$ bovine serum albumin (BSA) and then overlaid with antisera diluted 1:20 in PBS-5\% BSA for 2 hours. After washing, bound antibody was detected by sequential incubation with biotinylated anti-human immunoglobulin (IgM, IgG), streptavidin-linked alkaline phosphatase, and black alkaline phosphatase substrate. ${ }^{18}$ To estimate relative antibody binding, the amount of bound antibody was divided by total GSL as determined by scanning densitometry (antibody staining [area]/GSL quantity [area by charring]). Immunostaining with murine MoAbs and Stx were performed as previously described. ${ }^{4,23,24}$

\section{Statistical analysis}

Quantitative data were expressed as the mean and standard deviation (SD). Differences in relative GSL expression were compared by t test. Graphics and statistical analysis 
were performed with commercial software (Kaleidograph, Synergy Software, Reading, PA).

\section{RESULTS}

\section{Serology}

\section{RBC typing}

The patient's RBCs typed as group $\mathrm{O}, \mathrm{D}+, \mathrm{I}+\mathrm{Le}(\mathrm{a}-\mathrm{b}+), \mathrm{P}_{1}+$. RBCs were reactive with several anti-globo reagents by direct agglutination, including anti- $\mathrm{PP}_{1} \mathrm{P}^{\mathrm{k}}$, alloanti-P, MoAb MC631, and P-fimbriated E. coli (Table 3). The patient typed LKE-N with MoAb MC813-70: No agglutination was observed with ficin-treated patient RBCs after $4^{\circ} \mathrm{C}$ incubation or in the IAT with anti-mouse IgG (tube and gel method) ${ }^{2,4,18}$

The patient's DAT was weakly reactive $(1+)$ due to complement after transfusion of $2 \mathrm{RBC}$ units at a local facility. A DAT drawn after his last transfusion was 2+ (antiC3, 11 RBCs total). An acid eluate of both samples was negative by tube method at IS and after incubation at RT (15 min) and $4^{\circ} \mathrm{C}(30 \mathrm{~min}$, Table 3$)$.

\section{Serum findings}

The patient's plasma contained a weak RT panagglutinin reactive with 14 of $16 \mathrm{P}+$ RBCs: No agglutination was observed against $\mathrm{p}(\mathrm{n}=4), \mathrm{P}_{1}{ }^{\mathrm{k}}, \mathrm{P}_{2}{ }^{\mathrm{k}}, \mathrm{LKE}-\mathrm{N}(\mathrm{n}=2)$, and autologous RBCs (Table 3 ). Reactivity could be enhanced by 15 -minute RT incubation, 30 -minute incubation at $4^{\circ} \mathrm{C}$ $(4+)$, and use of ficin-treated RBCs. The direct agglutination titer against LKE-S RBC was 256 at $4^{\circ} \mathrm{C}$.
The plasma was nonreactive at $37^{\circ} \mathrm{C}$ with low-ionicstrength saline (30- or 60-min incubation) and in the IAT by tube and gel method with anti-IgG. The serum was weakly reactive in PEG-IAT cross-matches with some random-donor RBCs, but nonreactive with the same cells by a prewarmed technique. ${ }^{12,13}$ The serum caused hemolysis of ficin-treated, LKE-S cells in a two-stage IAT by tube method, using fresh normal serum as a source of complement and polyspecific anti-human globulin (Table 3). ${ }^{13}$

\section{Flow cytometry}

Patient cells were initially screened for $\mathrm{P}^{\mathrm{k}}, \mathrm{P}$, and LKE expression by flow cytometry. ${ }^{4}$ RBCs from LKE-S $(n=3)$, LKE-N, $\mathrm{P}_{1}{ }^{\mathrm{k}}$, and $\mathrm{p}$ individuals were included as controls. Consistent with serologic typing, little or no detectable LKE was identified on patient RBCs with MoAb MC813-70 (Fig. 2). Unlike the LKE-N and $\mathrm{P}_{1}{ }^{\mathrm{k}}$ controls, the patient had no evidence of increased $\mathrm{P}^{\mathrm{k}}$ expression. ${ }^{4,7}$ There was no significant difference in $\mathrm{P}^{\mathrm{k}}$ and $\mathrm{P}$ expression between the patient and the LKE-S controls.

\section{Neutral RBC GSLs}

To confirm the results of flow cytometry, GSLs from the patient's cells were isolated and analyzed by HPTLC. GSLs from human granulocytes and $\mathrm{P}_{1}{ }^{\mathrm{k}}$ and LKE-S RBCs were included as controls. Neutrophils, like p RBCs, are devoid of globo-GSLs and express predominantly neolactofamily GSLs (Table 4). ${ }^{23,25}$

\begin{tabular}{|c|c|c|c|c|c|c|c|c|c|c|c|c|c|}
\hline \multirow[b]{3}{*}{ Cell } & \multicolumn{8}{|c|}{ RBC typing ${ }^{*} \dagger$} & \multicolumn{5}{|c|}{ Serum testing $\ddagger$} \\
\hline & \multirow[b]{2}{*}{$\mathrm{ABO}$} & \multirow[b]{2}{*}{ Anti- $P_{1}$} & \multirow[b]{2}{*}{ Anti- $\mathrm{PP}_{1} \mathrm{P}^{\mathrm{k}}$} & \multicolumn{2}{|c|}{ Anti-P } & \multicolumn{2}{|c|}{ E. coli§ } & \multirow[b]{2}{*}{ LKE†† } & \multicolumn{3}{|c|}{ Direct Agglutinationll } & \multicolumn{2}{|c|}{ Two-stage IATף } \\
\hline & & & & MC631 & P-titer ${ }^{\star \star}$ & SC802 & $\mathrm{HB101}$ & & IS & $15 \mathrm{~min}, \mathrm{RT}$ & $60 \mathrm{~min}, 37^{\circ} \mathrm{C}$ & $\overline{\mathrm{AHG}}$ & Comments \\
\hline$p$ & $\mathrm{O}$ & 0 & 0 & 0 & 0 & 0 & 0 & $\mathrm{~N}$ & 0 & 0 & - & - & \\
\hline $\mathrm{P}_{1}{ }^{\mathrm{K}}$ & $\mathrm{O}$ & + & $3+$ & 0 & 0 & 0 & 0 & $\mathrm{~N}$ & 0 & 0 & - & - & \\
\hline 1 & $\mathrm{O}$ & + & - & $4+$ & 32 & 512 & 0 & $\mathrm{~N}$ & 0 & 0 & 0 & 0 & \\
\hline 2 & $\mathrm{O}$ & + & - & $3+$ & 16 & 256 & 0 & $\mathrm{~N}$ & 0 & $+1-$ & 0 & 0 & \\
\hline 3 & 0 & + & - & - & - & 1048 & 0 & W & - & $1 t^{w}$ & 0 & 0 & \\
\hline 4 & $\mathrm{O}$ & + & - & - & 32 & 256 & 0 & W & - & $1+^{w}$ & 0 & 0 & \\
\hline 5 & $\mathrm{O}$ & + & $3+$ & $4+$ & 32 & 512 & 0 & $S$ & $2+$ & $2+$ & 0 & $1+^{w}$ & Hemolysis \\
\hline 6 & $\mathrm{O}$ & + & - & $4+$ & 64 & 1048 & 0 & $S$ & $2+$ & $3+$ & 0 & $1 t^{\mathrm{m}}$ & Hemolysis \\
\hline 7 & O & + & - & - & - & - & - & $\mathrm{S}$ & $+1-$ & $1+^{\mathrm{s}}$ & 0 & $2+^{s}$ & \\
\hline 8 & 0 & + & - & - & - & - & - & $S$ & - & - & 0 & $2+$ & Hemolysis \\
\hline Pt. & $\mathrm{O}$ & $3+$ & $3+$ & $2+$ & 8 & 512 & 0 & $\mathrm{~N}$ & 0 & 0 & 0 & $1+^{w}$ & 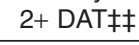 \\
\hline \multicolumn{14}{|c|}{$\begin{array}{l}\text { * A total of } 32 \text { RBC samples were tested against patient serum/plasma. Shown are the reactivity of cells used in the two-stage IAT and flow } \\
\text { cytometry (Fig. 2). }\end{array}$} \\
\hline \multicolumn{14}{|c|}{ 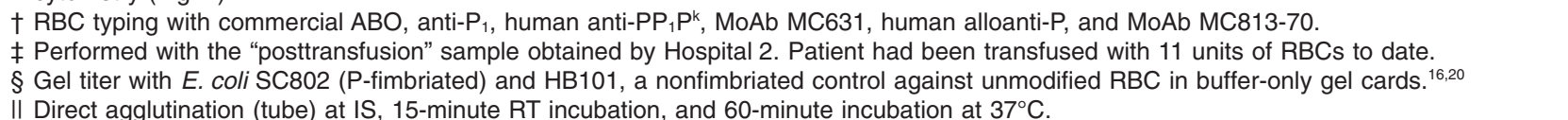 } \\
\hline \multirow{2}{*}{\multicolumn{14}{|c|}{$\begin{array}{l}\text { I Two-stage IAT performed with ficin-treated RBC, polyspecific AHG, and fresh plasma (serum) as a source of complement. }{ }^{13} \text { Cells were } \\
\text { chosen based on their LKE-phenotype as noted. } \\
\text { ** P-titer using human polyclonal alloanti-P with strict Gb4 specificity by HPTLC immunostaining. Testing performed with unmodified RBC } \\
\text { (buffer gel, } 1 \text { hour, } 4^{\circ} \mathrm{C} \text { ). Titer reported as the inverse dilution giving } 1+\text { agglutination. }\end{array}$}} \\
\hline & & & & & & & & & & & & & \\
\hline \multicolumn{14}{|c|}{ t† LKE phenotype as determined with MoAb MC81-70. } \\
\hline \multicolumn{14}{|c|}{$\begin{array}{l}\text { ҒҒ Patient had } 2+\text { DAT after transfusion with } 11 \text { units of RE } \\
-=\text { not done; } 0=\text { no agglutination; }+=\text { positive. Hemagglutir }\end{array}$} \\
\hline
\end{tabular}


A
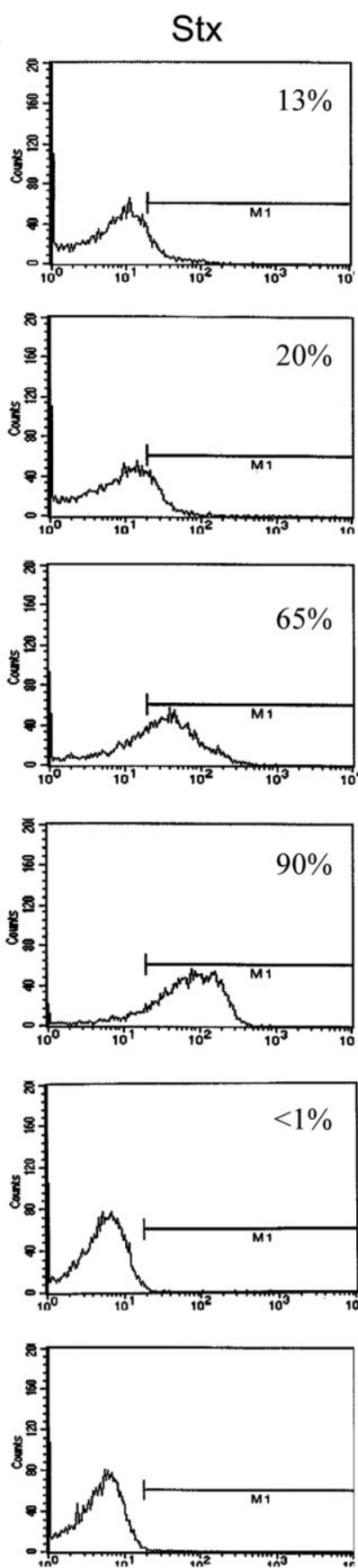

B

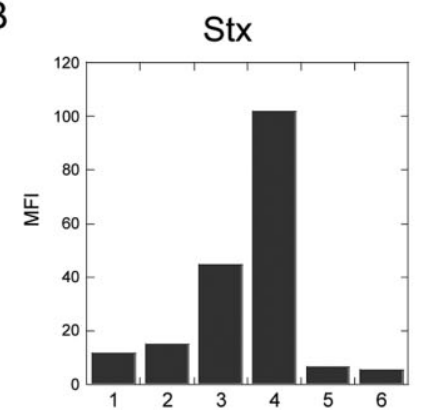

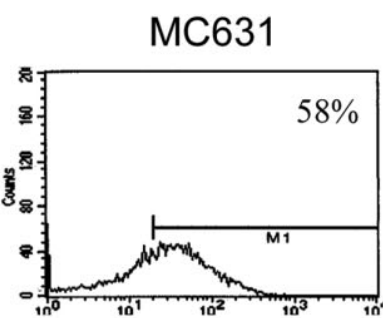
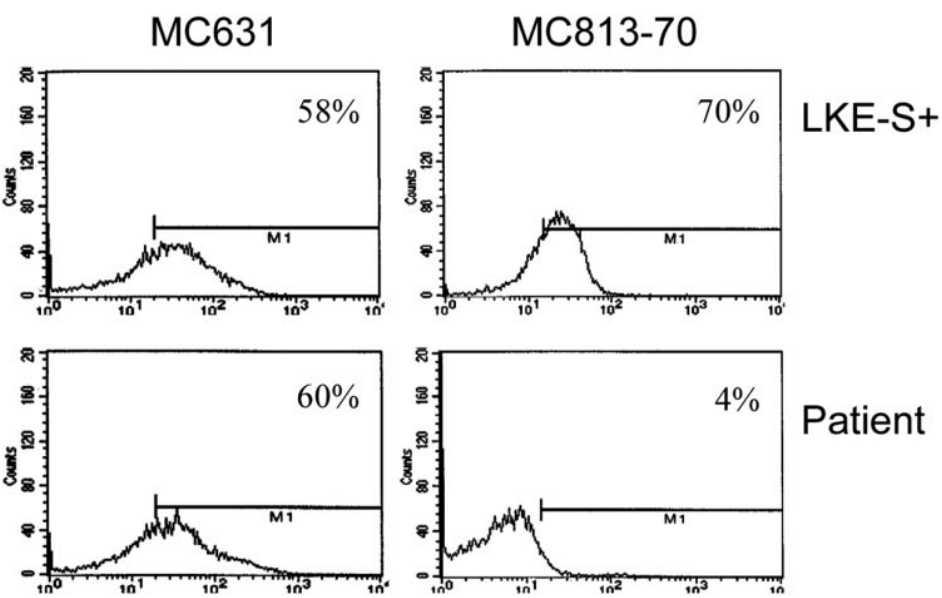

Patient
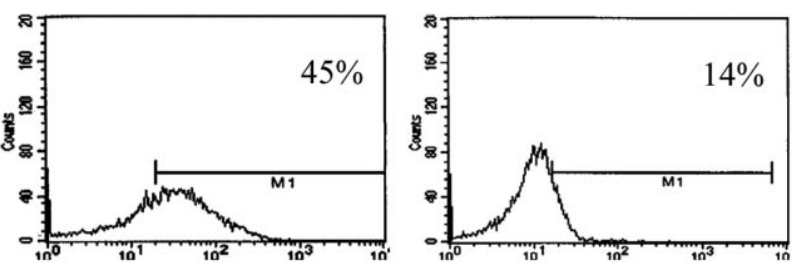

LKE-N
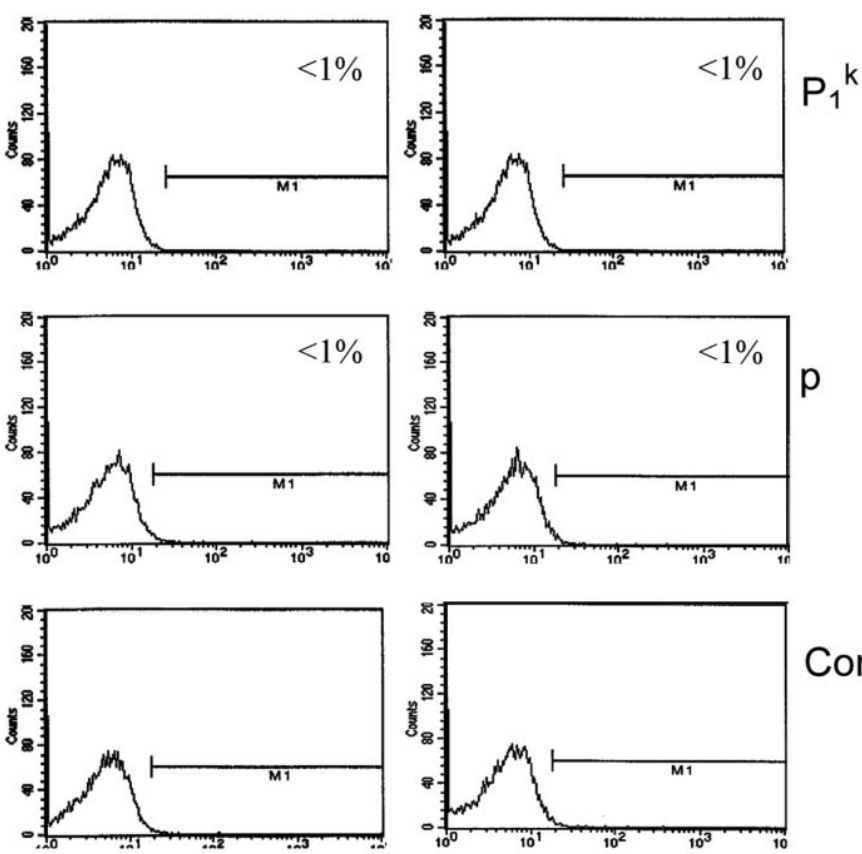

Control
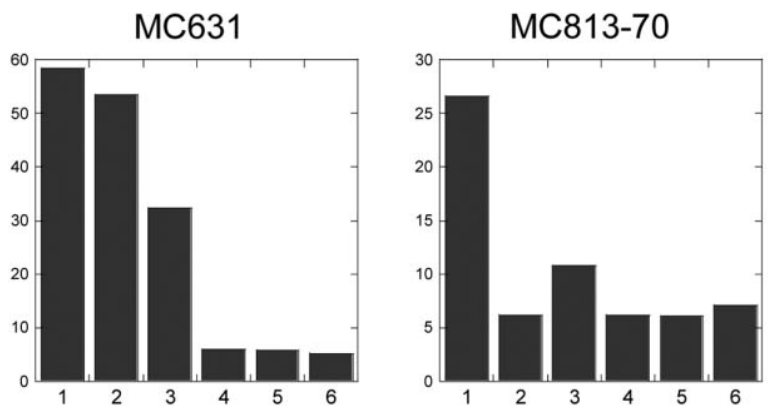
Fig. 2. Globo-GSL analysis by flow cytometry. (A) Flow cytometric histograms of patient, LKE-S, LKE-N, $P_{1}{ }^{k}$, and $p$ ficin-treated RBCs stained with FITC-Stx (anti-Gb3), MoAb MC631 (anti-Gb4), and MoAb MC813-70 (anti- LKE, Table 2). Patient sample is posttransfusion of 2 units of group 0 RBCs. Also included are negative isotype controls for murine IgM (anti-CD15), IgG (antiCD31), and Stx (FITC dialysate ${ }^{4}$ ). Line demarcates positively stained cells. Percentages indicate the percent positive cells for each marker. (B) The MFI of RBCs stained with Stx, MoAb MC631, and MoAb MC813-70. Lane 1 = LKE-S; Lane 2 = patient; Lane 3 = LKE-N; Lane 4 = P $_{1}{ }^{\mathrm{k}}$; Lane 5 = p; Lane 6 = negative control.

TABLE 4. Neutral GSL expression by $P$ and LKE type

\begin{tabular}{|c|c|c|c|c|c|c|c|c|c|}
\hline \multirow[b]{2}{*}{ RBCs } & \multirow[b]{2}{*}{$\mathrm{ABO}$} & \multirow[b]{2}{*}{ No.‡ } & \multicolumn{5}{|c|}{ Percent neutral GSL (normalized, mean $\pm \mathrm{SD})^{*}$} & \multicolumn{2}{|c|}{ Ratio (area) $†$} \\
\hline & & & $\mathrm{CMH}$ & $\mathrm{CDH}$ & Gb3 & Gb4 & nLc4 & $\mathrm{Gb3} / \mathrm{CDH}$ & Gb4/Gb3 \\
\hline \multirow[t]{3}{*}{ LKE-S } & $\mathrm{O}, \mathrm{A}$ & 8 & $1.3 \pm 0.7$ & $11.3 \pm 3.7$ & $23.5 \pm 3.0$ & $58.4 \pm 3.6$ & $4.4 \pm 0.6$ & $2.38 \pm 0.80$ & $2.45 \pm 0.44$ \\
\hline & $\mathrm{O}$ & 4 & $1.3 \pm 0.7$ & $10.3 \pm 1.9$ & $24.4 \pm 2.5$ & $57.7 \pm 3.2$ & $4.4 \pm 0.6$ & $2.56 \pm 0.45$ & $2.22 \pm 0.16$ \\
\hline & A & 4 & $1.3 \pm 0.8$ & $11.1 \pm 1.9$ & $21.6 \pm 5.6$ & $54.2 \pm 4.6$ & $2.3 \pm 0.5$ & $2.20 \pm 1.08$ & $2.67 \pm 0.54$ \\
\hline LKE-N§ & $\mathrm{A}, \mathrm{B}, \mathrm{O}$ & 3 & $2.3 \pm 1.3$ & $11.1 \pm 1.9$ & $31.6 \pm 5.6$ & $54.2 \pm 4.6$ & $4.3 \pm 0.7$ & $2.90 \pm 0.65$ & $1.75 \pm 0.43$ \\
\hline $\mathrm{P}^{\mathrm{k}}$ variantll & $\mathrm{O}$ & 1 & NR & 11.6 & 63.8 & 24.6 & NR & 5.52 & 0.38 \\
\hline$P_{1}^{k}$ & A & 1 & $1.5 \pm 0.4$ & $33.9 \pm 3.7$ & $52.0 \pm 3.2$ & 0 & $11.5 \pm 1.6$ & $1.65 \pm 0.02$ & 0 \\
\hline Weak Pף & $A$ & 1 & NR & 22.5 & 16.7 & 40.2 & 20.6 & 0.73 & 2.41 \\
\hline Patient & $\mathrm{O}$ & 1 & $0.7 \pm 0.1$ & $30.6 \pm 0.3$ & $13.5 \pm 1.8$ & $42.7 \pm 4.0$ & $12.3 \pm 4.6$ & $0.47 \pm 0.06$ & $3.15 \pm 0.44$ \\
\hline$p\left(P_{1} P^{k}-\right)^{\star \star}$ & NR & 4 & $7.2 \pm 0.6$ & $67.4 \pm 2.9$ & 0 & 0 & $13 \pm 2.1$ & 0 & 0 \\
\hline Granulocytes & $\mathrm{B}$ & 1 & $1.9 \pm 0.6$ & $75.8 \pm 2.1$ & 0 & 0 & $18.2 \pm 2.9$ & 0 & 0 \\
\hline Patient vs. LKE-S†† & & & NS & $<0.0001$ & 0.009 & 0.002 & 0.0005 & 0.03 & 0.046 \\
\hline Patient vs. LKE-N†† & & & NS & $<0.0001$ & 0.006 & 0.031 & 0.019 & 0.003 & 0.017 \\
\hline
\end{tabular}

* Relative distribution of $\mathrm{CMH}, \mathrm{CDH}, \mathrm{Gb3}, \mathrm{Gb} 4$, and nLc4 as determined by scanning densitometry. The percentages were normalized to equal $100 \%$.

† Substrate/product ratios for Gb3 (Gb3/CDH) and Gb4 (Gb4/Gb3) synthesis, as determined by scanning densitometry.

$\ddagger$ Number of RBC GSLs tested or published in the literature.

$\S$ Data taken from Cooling and Kelley. ${ }^{4}$

II Data taken from Kundu et al. ${ }^{8}$

ๆ Data from Kundu et al. ${ }^{11}$

** Data taken from Kundu et al. ${ }^{25}$ Lactotriaosylceramide (Lc3) content of $p$ RBC averaged $12.2 \pm 1.4 \% .{ }^{26}$

†† t-test.

$N A=$ not applicable; $N R=$ not reported; NS = not significant $(p>0.05)$.

Normal RBCs express four major neutral GSLs (Fig. 3A): glucosylceramide $\left(\mathrm{CMH}, \mathrm{R}_{\mathrm{f}}=0.59\right)$, lactosylceramide $\left(\mathrm{CDH}, \mathrm{R}_{\mathrm{f}}=0.40\right)$, globotriaosylceramide (Gb3, $\left.\mathrm{R}_{\mathrm{f}}=0.25\right)$, and globoside $\left(\mathrm{Gb} 4, \mathrm{R}_{\mathrm{f}}=0.16\right)$. Patient $\mathrm{RBCs}$ (Fig. 3A, Lane 7) displayed a $40 \%$ decrease in Gb3 and a $25 \%$ decrease in $\mathrm{Gb} 4$, for an overall $30 \%$ decrease in globoGSLs relative to LKE-S controls (Table 4). Decreased globo-GSLs were accompanied by a threefold increase in $\mathrm{CDH}$ and increased expression of a paragloboside-like GSL (nLc4, $R_{f}=0.13$ ). An increase in $\mathrm{CDH}$ and nLc4 were also observed in a $\mathrm{P}_{1}{ }^{\mathrm{k}}$ control.

Neutral GSLs were subsequently immunostained with reagents against Gb3 (Stx, Fig. 3B), ${ }^{4}$ Gb4 (MoAb MC631, Fig. 3C), ${ }^{14}$ and nLc4 (MoAb FeA5, Fig. 3D; Table 2$)^{15}$ to verify the results of chemical staining. The patient had weak Stx staining to Gb3 and $\mathrm{P}_{1}$ (Fig. 3D, Lane 7). Likewise, MC631 staining to Gb4 was reduced $50 \%$ relative to LKE-S RBCs. Strong FeA5 staining to nLc4 was observed in patient, $\mathrm{P}_{1}{ }^{\mathrm{k}}$, and a neutrophil control.

As an indirect measure of relative glycosyltransferase activity, the ratio of product to substrate was determined by scanning densitometry (Table 4). ${ }^{28,29}$ Unlike LKE-N RBCs, ${ }^{4}$ patient cells had a relatively normal Gb4/Gb3 ratio. In contrast, there was a fivefold decrease in the Gb3/CDH ratio, consistent with decreased conversion of $\mathrm{CDH} \rightarrow \mathrm{Gb} 3$. A decrease in $\mathrm{Gb} 3 / \mathrm{CDH}$ ratio, accompanied by increases in $\mathrm{CDH}$ and $\mathrm{nLc} 4$, is also reported for the weak P phenotype. ${ }^{11}$ As shown, relative neutral GSL expression in our patient and a known weak $P$ sample was virtually identical (Table 4).

\section{RBC gangliosides}

HPTLC analysis of the total RBC ganglioside fraction showed subtle but significant differences in ganglioside expression between patient (Fig. 3E, Lane 3), $\mathrm{P}_{1}{ }^{\mathrm{k}}$ (Fig. 3E, Lane 2), and LKE-S RBCs (Fig. 3E, Lanes 4-6). All RBCs expressed ganglioside GM3 $\left(\mathrm{R}_{\mathrm{f}}=0.48\right)$ and sialoparagloboside (snLc4, $\mathrm{R}_{\mathrm{f}}=0.38$ ), which together comprised $60 \%$ to $70 \%$ of the total RBC ganglioside by scanning densitometry (Figs. 3H-3J). In LKE-S cells, the ratio of snLc4: GM3 was approximately 2:1, with snLc4 representing nearly $50 \%$ of the total RBC ganglioside. In patient and $\mathrm{P}_{1}{ }^{\mathrm{k}}$ RBCs, the snLc4:GM3 ratio was reduced (1:1) due to a $20 \%$ relative increase in GM3 expression (Figs. 3H and 3I). All RBC samples, including the patient's, had evidence of snLc6 and long-chain, high-molecular-weight (HMW) Type 2 sialylated gangliosides ${ }^{30-32}$ upon immunostaining with MoAb FeA5 (Fig. 3F). ${ }^{15,24}$ 


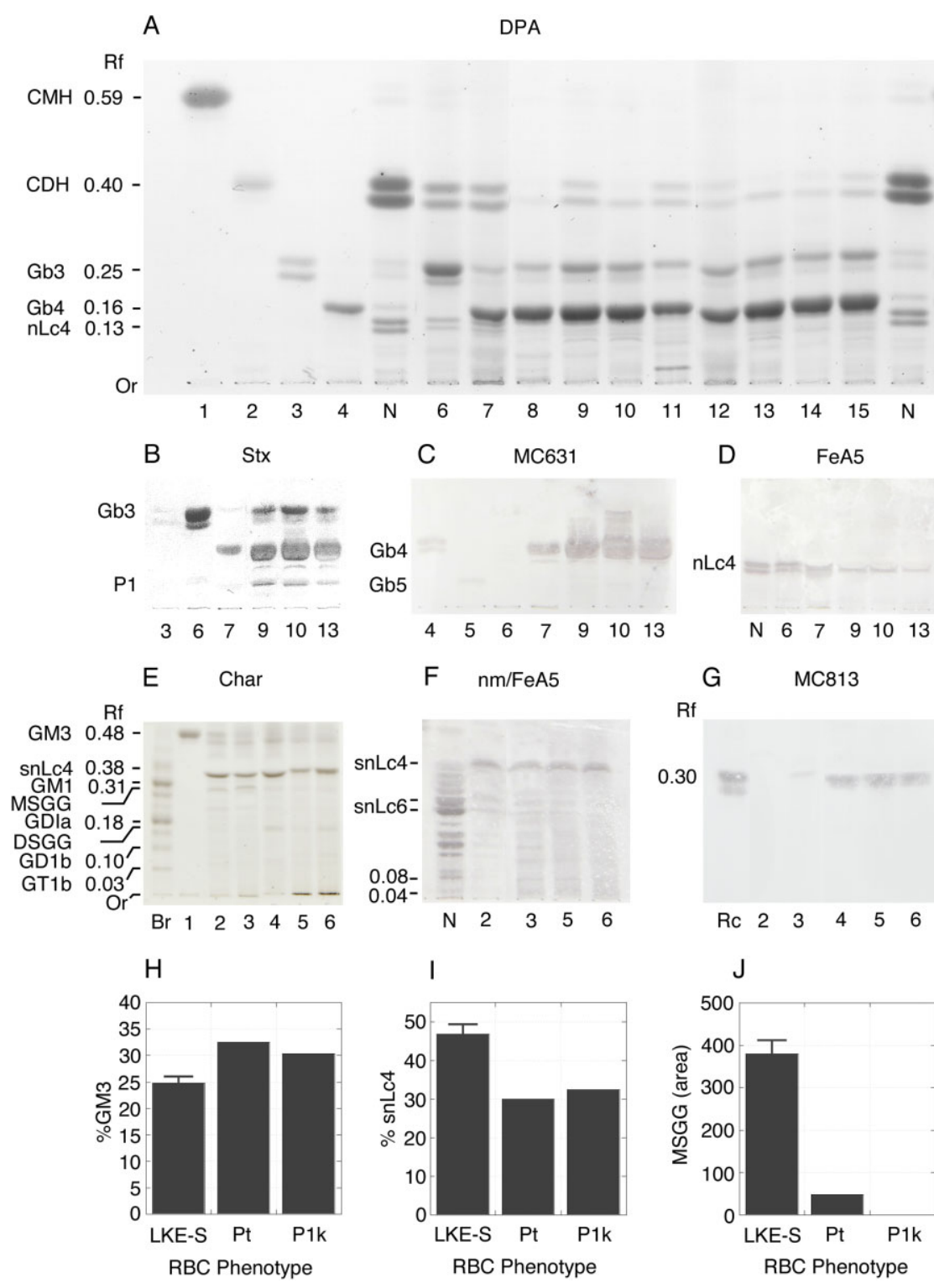

Fig. 3. HPTLC analysis of isolated RBC GSLs. (A-D) Neutral RBC GSLs chemically stained with (A) diphenylamine reagent, (B) Stx, (C) MoAb MC631, and (D) MoAb FeA5. Note faint Stx binding due to high Gb4 concentrations. ${ }^{26,27}$ Lane $1=\mathrm{CMH}$; Lane 2 = CDH; Lane 3 = Gb3 ( $\mathrm{P}^{\mathrm{k}}$ antigen); Lane 4 = Gb4 (P antigen); $\mathrm{N}$ = neutrophils; Lane $6=P_{1}{ }^{k}$ RBCs; Lane 7 = patient; Lanes 8 through 11, group A LKE-S RBCs; Lanes 12 through 16 = group O, LKE-S RBCs. Each RBC lane contains total neutral GSL from approximately $250 \mu \mathrm{L}$ of RBC. Neutral GSLs were separated in neutral solvent C-M-W, 65:25:4 vol/vol. (E-G) RBC gangliosides stained by (E) charring reagent, (F) neuraminidase/FeA5, ${ }^{24}$ and (G) MoAb MC813-70. MSGG identified in ACHN control $\left(R c, R_{f}=0.30\right)$ and LKE-S RBCs, with only faint band in patient sample. Lane $1=$ GM3 standard; Lane $2=\mathrm{P}_{1}{ }^{\mathrm{k}} \mathrm{RBCs}$; Lane 3 = patient; Lanes 4 through 6 = LKE-S RBC; $\mathrm{Br}=$ human brain; Rc = ACHN renal carcinoma cell (MSGG+, DSGG+); N = neutrophils. Gangliosides were separated in $\mathrm{C}-\mathrm{M}-0.2 \%$ aqueous $\mathrm{CaCl}_{2}$ 50:40:10 vol/vol. Each RBC lane contains the total ganglioside fraction from approximately $500 \mu \mathrm{L}$ of RBCs. (H-J) Scanning densitometry of RBC gangliosides showing (H) percent GM3, (I) percent snLc4, and ( $\mathrm{J}$ ) relative concentration of MSGG based on MoAb MC813-70 staining.
To identify MSGG/LKE antigen, RBC gangliosides were immunostained with MoAb MC813-70 (Fig. 3G) ${ }^{1,2}$ ACHN cells were included as an MSGGpositive control. ${ }^{33,34}$ As shown, a strong MC813-70 band was identified in the ACHN control (Rc, $\left.R_{f}=0.30\right)$ and all three LKE-S RBCs. A faint, but detectable MC813-70 band was identified in the patient sample (Fig.3G, Lane 3). Based on MC813-70 staining intensity, MSGG in patient samples was $10 \%$ that observed in LKE-S RBCs ( $p=0.001$, Fig. 3J). As expected, no staining was observed in $\mathrm{P}_{1}{ }^{\mathrm{k}}$ cells, which lack Gb4 and longer chain globo-GSLs.

\section{Titration of globo-antigens on patient RBCs}

The weak $\mathrm{P}$ phenotype is reported to show weakened $\mathrm{P}$ expression in titration studies with some examples of anti$\mathrm{PP}_{1} \mathrm{P}^{\mathrm{k}}{ }^{11}$ In titration studies, the patient had a significantly decreased titer with one alloanti-P (titer, 8) relative to LKE-N $(\mathrm{n}=3$; median titer, 16$)$, LKE-W $(\mathrm{n}=4$; titer, 16-32), and LKE-S cells ( $\mathrm{n}=4$; titer, 32-128). ${ }^{18}$ No difference was observed with a second alloanti-P sample (data not shown).

We also performed titration studies with SC802, a recombinant P-fimbriated E. coli strain (Table 3). ${ }^{16,20}$ The P-fimbria adhesion recognizes all globo-GSLs but is reported to preferentially recognize MSGG. ${ }^{35,36}$ There was no difference in agglutination titer or Marsh score (not shown) between patient and LKE-S RBCs. As expected, no agglutination was observed with $p$ RBCs, which are devoid of globo-GSLs, or with HB101, a nonfimbriated E. coli control.

\section{Patient's antibody recognizes MSGG and Gb5}

To confirm that the patient's anti-LKE recognized MSGG, we performed HPTLC-immunostaining with patient serum against isolated RBC gangliosides from LKE-S, $\mathrm{P}_{1}{ }^{k}$, and the patient (Fig. 4). GSLs from ACHN cells were also included as a control. ${ }^{33}$ Patient 

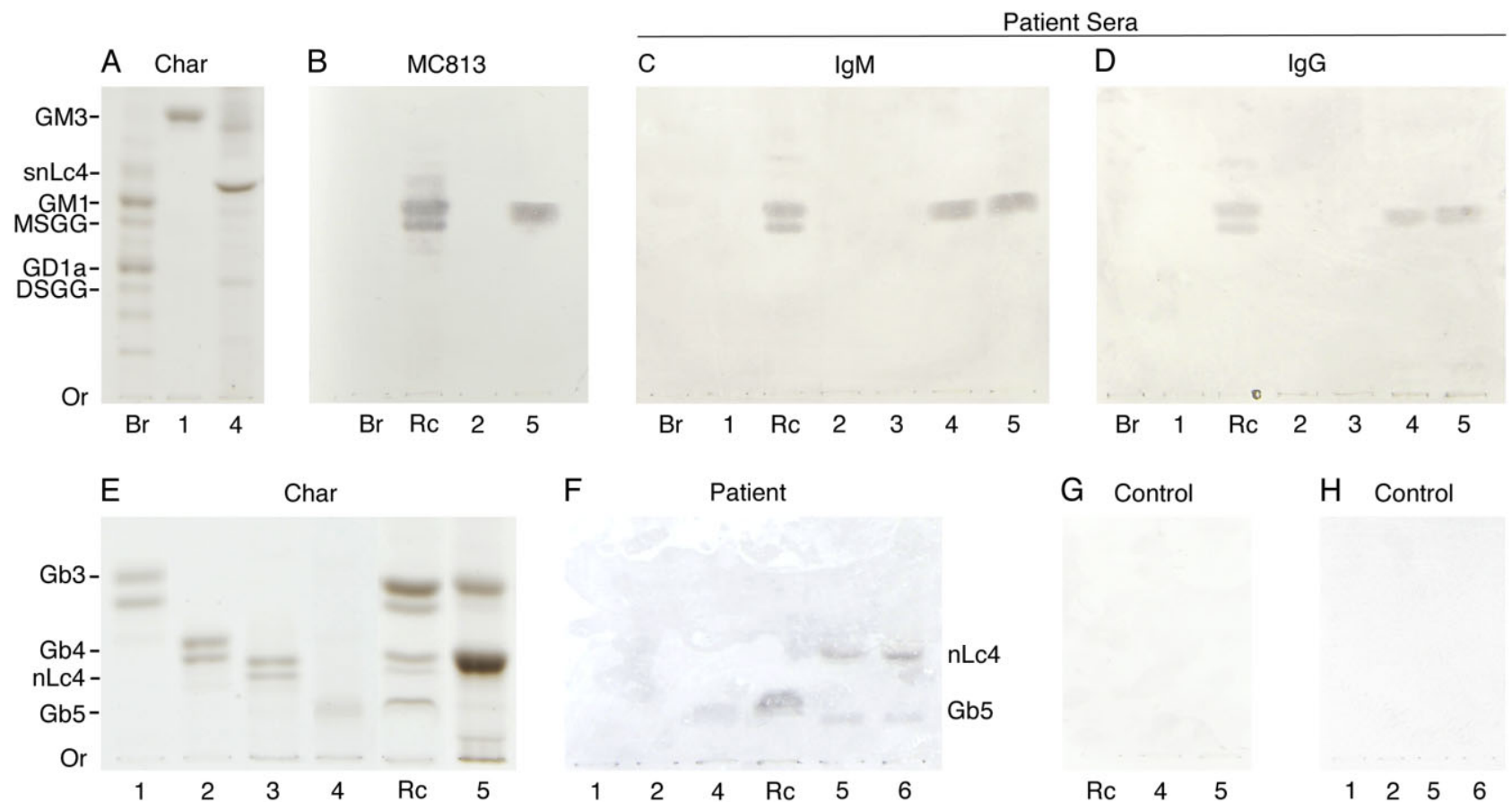

G Control

H Control

Fig. 4. Patient sera binds MSGG and Gb5 by HPTLC immunostaining. (A-D, G) Gangliosides stained with (A) charring reagent, (B) MoAb MC813-70, (C) patient serum and anti-human IgM, (D) patient serum and anti-IgG, and (G) control serum, anti-IgM. Patient serum recognized MSGG in ACHN and LKE-S RBCs. Patient serum did not recognize DSGG present in ACHN cells. Very faint IgG binding to HMW Ii-active gangliosides $\left(R_{\mathrm{f}}=0.08,0.04\right)$ was also observed. Lane $1=\mathrm{GM3}$ standard; Lane $2=\mathrm{P}_{1}{ }^{\mathrm{k}} \mathrm{RBCs}$; Lane

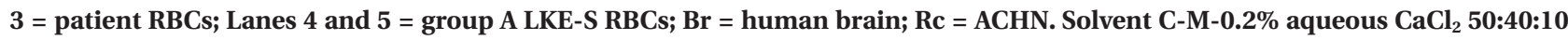
vol/vol. (E, F, and H) Neutral GSLs stained with (E) charring reagent, (F) patient serum, or (H) normal control. Lane 1 = Gb3; Lane 2 = Gb4 standard; Lane 3 = nLc4 standard; Lane $4=$ Gb5 standard; Rc = ACHN; Lanes 5 and $6=$ RBC neutrals. Secondary antibody (F, H) was anti-human IgM. Solvent C-M-W 65:25:4 vol/vol.

serum strongly bound MSGG in ACHN and LKE-S RBCs: no staining was observed to patient and $\mathrm{P}_{1}{ }^{\mathrm{k}}$ RBCs. The patient's antibody did not recognize GM3, ganglio-series gangliosides (Br, Table 2), or disialogalactosylgloboside (DSGG, Table 2; ACHN cells ${ }^{37}$ ). The alloanti-LKE present in patient serum included both anti-human IgM (Fig. 4C) and anti-IgG (Fig. 4D). Very faint binding to two HMW RBC gangliosides $\left(\mathrm{R}_{\mathrm{f}}=0.08\right.$, 0.04), consistent with complex sialyl-Ii gangliosides (Fig. 3F), was observed with anti-IgG only.

We also tested patient serum against neutral GSLs. Faint binding was observed to galactosylgloboside (Gb5, Fig. 4F), the immediate biosynthetic precursor to MSGG. On scanning densitometry, the patient's sera preferentially recognized MSGG over Gb5 when normalized for the amount of GSL present ( $p=0.0001$; Fig. 5C). Antibody binding was also observed to a GSL band near Gb4 in RBCs, but not in ACHN cells or the Gb4 control. Subsequent studies confirmed that patient sera contained antibodies recognizing nLc4 (data not shown). Antibody binding to nLc4 was also observed in one normal control (Table 5).

\section{Reactivity of other globo antibodies to MSGG}

We subsequently screened a series of human polyclonal globo antibodies including alloanti- $\mathrm{PP}_{1} \mathrm{P}^{\mathrm{k}}$, alloanti-P, and an autoanti-P from a patient with paroxysmal cold hemoglobinuria (PCH). Results of human polyclonal reagents were compared to known anti-globo MoAbs and lectins (Table 5). Relative antibody binding to individual GSLs was determined by scanning densitometry (Fig. 5C).

To confirm antibody activity and specificity, antisera was initially tested against neutral GSLs (Fig. 5A). As expected, sera from $p$ individuals reacted with $\mathrm{Gb}_{3}, \mathrm{~Gb}_{4}$, and $\mathrm{P}_{1}$ antigen with a preference for Gb3 (Fig. 5C). Heterogeneous activity was observed with alloanti-P from $\mathrm{P}^{\mathrm{k}}$ individuals, with some examples showing nearly pure anti-P activity and other examples displaying broader reactivity (Table 5, Fig. 5C). Four examples of alloanti-P showed activity against Gb5. PCH serum was specific for Gb4, as was a historical low-titer "anti-LKE" (UM1314, Table 5). ${ }^{6,18}$

When tested against gangliosides (Fig. 5B), two alloanti-P recognized MSGG, with one example showing 


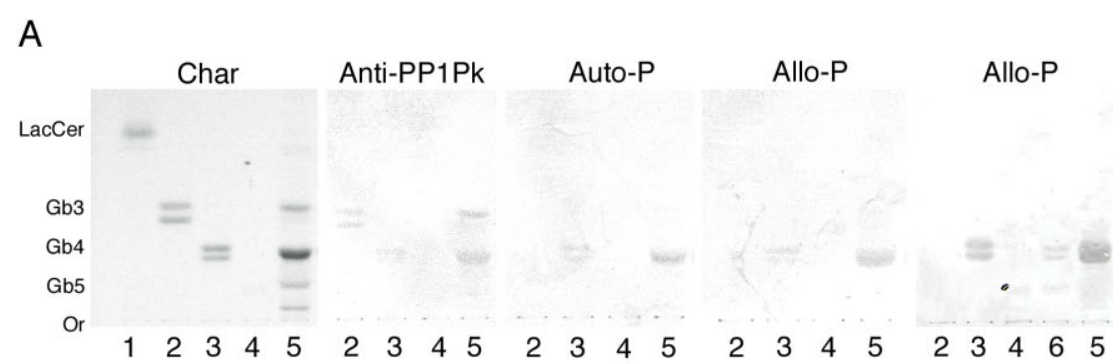

B

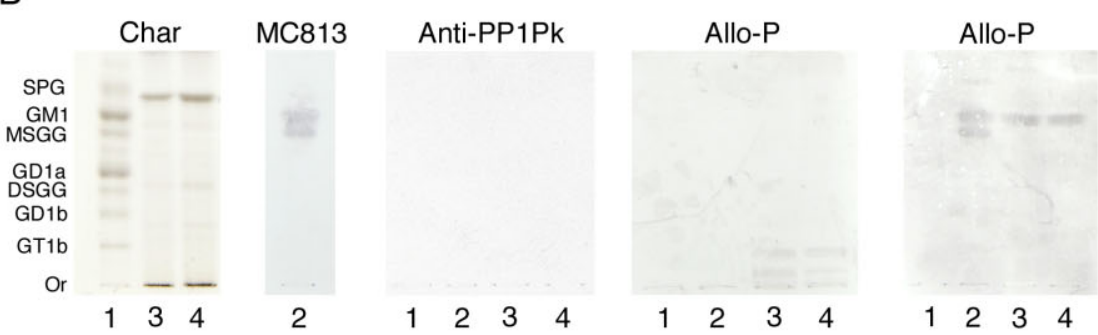

C
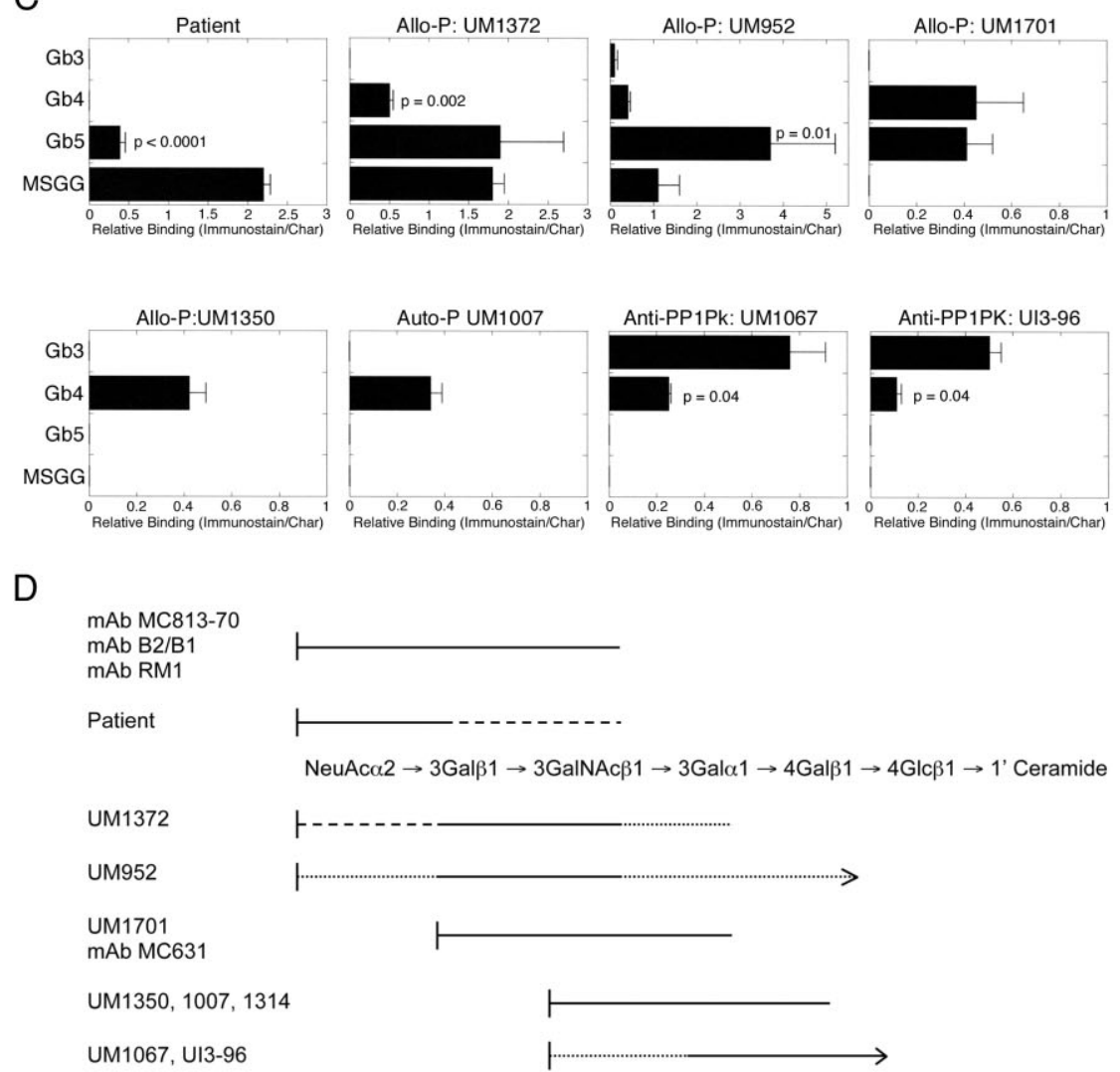

Fig. 5. Relative binding and epitope mapping of globo antibodies. (A) Neutral GSLs stained by charring or with human anti-PP1Pk, auto-P (PCH), and alloanti-P serum. Antibody staining detected with human anti-IgM. Lane 1 = CDH; Lane 2 = Gb3; Lane 3 = Gb4; Lane 4 = Gb5; Lane 5 = RBCs; Lane 6 = ACHN. Solvent C-M-W 65:25:4 vol/vol. (B) Gangliosides stained by charring, MoAb MC81370, anti-PP ${ }_{1} \mathrm{P}^{\mathrm{k}}$, and alloanti-P. Lane 1 = Brain; Lane 2 = ACHN; Lanes 3 and 4 = LKE-S RBCs. Solvent C-M-0.2\% aqueous CaCl 2 vol/ vol. (C) Relative antibody binding to Gb3, Gb4, Gb5, and MSGG. Relative binding determined by scanning densitometry (area [immunostain]/area [charring]). (D) Epitope mapping of anti-globo antibodies. Both patient's anti-LKE and many alloanti-P recognize the Gal $\beta 1 \rightarrow 3$ GalNAc motif present in Gb5 and MSGG. The patient's anti-LKE was significantly enhanced by the presence of a terminal $\alpha 2 \rightarrow 3$ sialic acid. Relative binding ( - = strong; - - - = moderate; $\cdots$, weak). 


\begin{tabular}{|c|c|c|c|c|c|c|c|c|c|c|c|}
\hline & \multicolumn{6}{|c|}{ Neutral GSLs } & \multicolumn{5}{|c|}{ Gangliosides } \\
\hline & $\overline{\mathrm{CDH}}$ & Gb3 & Gb4 & Gb5 & P1 & $\mathrm{nLc4}$ & GM3 & snLc4 & MSGG & DSGG & Sialyl-li \\
\hline \multicolumn{12}{|l|}{ Human } \\
\hline Anti- $\mathrm{PP}_{1} \mathrm{P}^{\mathrm{k} *}$ & $0 / 5$ & $5 / 5$ & $5 / 5$ & $0 / 5$ & $5 / 5$ & $0 / 5$ & $0 / 2$ & $0 / 2$ & $0 / 2$ & $0 / 2$ & $0 / 2$ \\
\hline Allo-P* & $0 / 8$ & $3 / 8$ & $8 / 8$ & $4 / 8$ & $0 / 8$ & $0 / 8$ & $0 / 4$ & $0 / 4$ & $2 / 4$ & $0 / 4$ & $1 / 4$ \\
\hline $\mathrm{PCH}$ & 0 & 0 & ++ & 0 & 0 & 0 & 0 & 0 & 0 & 0 & 0 \\
\hline UM13146,18 & 0 & 0 & + & 0 & 0 & 0 & 0 & + & 0 & 0 & w+ \\
\hline Patient & 0 & 0 & 0 & + & 0 & + & 0 & 0 & +++ & 0 & w+ \\
\hline Normal $^{*}$ & $0 / 8$ & $0 / 8$ & $0 / 8$ & $0 / 8$ & $0 / 8$ & $1 / 8$ & $0 / 6$ & $0 / 6$ & $0 / 6$ & $0 / 6$ & $0 / 6$ \\
\hline \multicolumn{12}{|l|}{ Murine } \\
\hline MC631 $1^{14}$ & 0 & 0 & ++ & ++ & 0 & 0 & 0 & 0 & $+1-$ & 0 & 0 \\
\hline $\mathrm{Nm} / \mathrm{MC} 631^{1} \dagger$ & 0 & 0 & ++ & ++ & 0 & 0 & 0 & 0 & +++ & ++ & 0 \\
\hline MC813-70 & 0 & 0 & 0 & 0 & 0 & 0 & 0 & 0 & +++ & 0 & 0 \\
\hline $\mathrm{B} 2 / \mathrm{B} 1^{34}$ & 0 & 0 & 0 & 0 & 0 & 0 & 0 & 0 & + & 0 & 0 \\
\hline $\mathrm{RM} 1^{34,37,38}$ & 0 & 0 & 0 & 0 & 0 & 0 & 0 & 0 & ++ & 0 & 0 \\
\hline $5 \mathrm{~F} 3^{37}$ & 0 & 0 & 0 & 0 & 0 & 0 & 0 & 0 & 0 & ++ & 0 \\
\hline \multicolumn{12}{|l|}{ Lectins } \\
\hline Stx & 0 & +++ & $+1-$ & 0 & + & 0 & 0 & 0 & 0 & 0 & 0 \\
\hline E. coli SC 802 & 0 & + & + & + & + & 0 & 0 & 0 & + & + & 0 \\
\hline E. coli HB101 & 0 & 0 & 0 & 0 & 0 & 0 & 0 & 0 & 0 & 0 & 0 \\
\hline
\end{tabular}

stronger reactivity to MSGG and Gb5 than Gb4 (UM1372; Figs. 5B and 5C). No binding to MSGG was noted by $\mathrm{PCH}$, anti- $\mathrm{PP}_{1} \mathrm{P}^{\mathrm{k}}, \mathrm{UM} 1314$, or normal control sera (Table 5). No sample tested recognized human brain gangliosides.

\section{DISCUSSION}

The first example of alloanti-LKE was identified in "Mr. Luke P.," a 32-year-old, group B, P+, untransfused, African American man with diffuse Hodgkin's lymphoma. ${ }^{5}$ Serologic studies showed that this "anti-Luke" recognized a high-incidence RBC antigen that was expressed by $\mathrm{P}_{1}$ and $\mathrm{P}_{2}$ donors, but not on rare $\mathrm{p}$ and $\mathrm{P}^{\mathrm{k}} \mathrm{RBCs}$, suggesting that the Luke antigen was related to the globo-GSL family. This was strengthened by family and population studies showing increased $\mathrm{P}^{\mathrm{k}}$ expression on LKE-N RBCs. ${ }^{4,7}$ Over the next decade, four additional anti-Luke were identified in $\mathrm{P}+$ individuals. ${ }^{6,7,10}$ Unlike the original anti-Luke, these later examples were low-titer panagglutinins (Table 1). Despite a $1 \%$ incidence of LKE-N in the general population, anti-LKE remains a rarely encountered antibody. The latter may reflect the fact that LKE is also expressed on many nonerythroid tissues. ${ }^{4,39-43}$

The formal identification of "Luke" as the globoganglioside MSGG occurred in 1988 with the demonstration that MoAb MC813-70, a MoAb developed against murine embryonic stem cells, had "Luke-like" activity in serologic testing. ${ }^{1,2}$ This was also consistent with the known RBC serology since MSGG would be absent on $p$ and $\mathrm{P}^{\mathrm{k}} \mathrm{RBC}$ due to the absence of required upstream GSL precursors necessary for MSGG synthesis (Fig. 6). With the presumed identification of MSGG as "Luke," the antigen was officially renamed LKE for "Luke antigen on erythro- cytes." ${ }^{3}$ Direct evidence of human anti-LKE binding to MSGG, or any other RBC GSL, has been lacking due to the scarcity of anti-LKE antisera.

We now present a sixth case of alloanti-LKE. Like the original Mr. Luke P., the anti-LKE in our patient was a high-titer, complement-fixing, direct agglutinin capable of in vitro hemolysis in a two-stage IAT with enzymetreated RBCs. Unlike previous anti-LKE described, ${ }^{5-7,10}$ our patient's antibody was also clinically significant with evidence of shortened RBC survival, a positive DAT, and laboratory evidence of hemolysis in vivo. It is interesting that the only two known high-titer anti-LKE both occurred in male patients with newly diagnosed lymphoma, raising the possibility that anti-LKE arose in response to malignancy. Carbohydrate antibodies are not uncommon in patients with advanced lymphoma, which commonly express Gb3, Gb4, and GM1 (Galß1-3GalNAc, Table 2). ${ }^{44-47}$ Globo-specific antibodies have been reported in other globo-rich cancers. ${ }^{48-52}$

We were also able to demonstrate, for the first time, direct binding of a human anti-LKE to MSGG, thus confirming MSGG as the LKE antigen. In addition to MSGG, the patient's antibody showed weak reactivity to Gb5, the biosynthetic precursor to MSGG. Gb5 is also recognized by MoAb MC631 and many alloanti-P. Furthermore, alloanti-P demonstrating strong Gb5 binding also recognized MSGG, suggesting that the Gal $\beta 1 \rightarrow 3$ GalNAc $\beta 1-R$ may be a common epitope among alloanti-P (Fig. 5D). Our findings complement an earlier study by Hansson and colleagues, ${ }^{53}$ who demonstrated broad reactivity by a high-titer alloanti-P, which recognized Gb4, Gb5, Forssman, and a placental ganglioside running near snLc4. The demonstration of alloanti-P with anti-LKE 


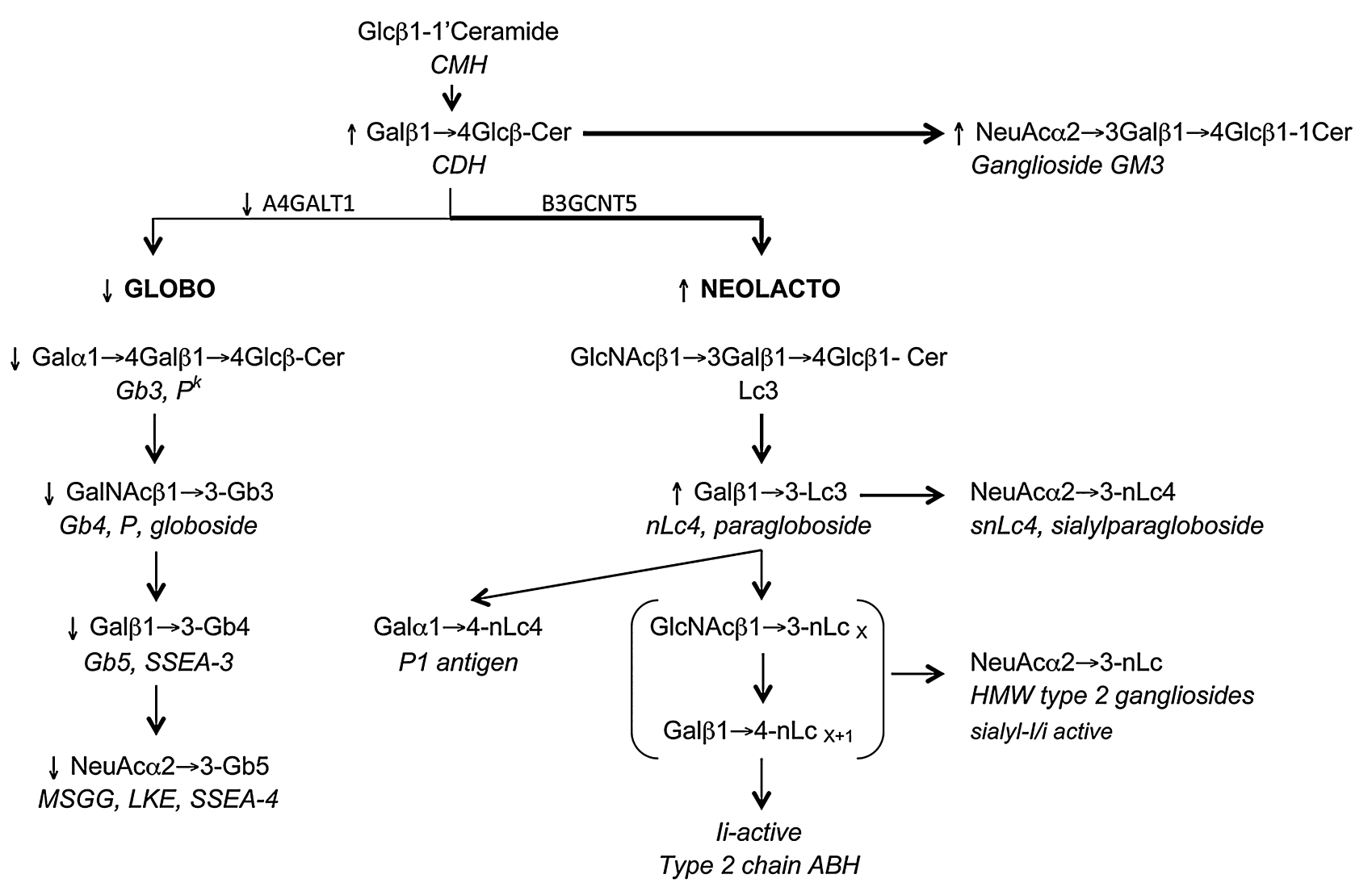

Fig. 6. Schematic of GSL synthesis in patient and weak $P$ individuals. Unlike normal individuals, there is an apparent decrease in $\alpha 4$ GalT1 activity, the first committed enzyme for globo-GSL synthesis. As a result, there is a global decrease in all globo-GSLs including $P^{k}, P$, and LKE and a compensatory increase in neolacto-series GSLs. There is also an increase in CDH and GM3 in these individuals.

activity suggests that some examples of alloanti-P could behave as an anti-P/LKE with stronger reactivity against LKE-S RBCs due to higher expression of both P and LKE antigens (Table 3).

Most examples of LKE-N described to date share features of the $\mathrm{P}^{\mathrm{k}}$ variant phenotype, with elevated $\mathrm{Gb} 3 / \mathrm{P}^{\mathrm{k}}$ expression..$^{4,8}$ Our patient is the first known example of LKE-N arising from a weak P phenotype and is only the second example of weak $\mathrm{P}$ characterized in the literature. The first weak $P$ was identified serendipitously in a normal donor after routine phenotyping showed weaker agglutination with some anti- $\mathrm{PP}_{1} \mathrm{P}^{\mathrm{k}} .{ }^{11}$ Analysis of the donor's RBC GSLs showed a 30\% decrease in globo-GSL expression, accompanied by a two- to fourfold increase in $\mathrm{CDH}, \mathrm{nLc} 4, \mathrm{GM} 3$, and total RBC ganglioside. As we have shown, our patient also displayed significant decreases in Gb3 and Gb4 with compensatory increases in $\mathrm{CDH}, \mathrm{nLc} 4$, and GM3. In fact, a comparison of relative neutral RBC GSL expression between our patient and the original weak $\mathrm{P}$ are virtually identical (Table 4$)$. Unlike our patient, the original weak $\mathrm{P}$ donor was of Chinese ancestry and did not possess any atypical RBC antibodies in his plasma.
The etiology of the weak P phenotype is unknown. Kundu and coworkers ${ }^{11}$ hypothesized a partial block in $\alpha 4 \mathrm{GalT1}$, the $\alpha 1,4$-galactosyltransferase responsible for Gb3 synthesis. As a result, weak P RBCs have a decrease in all globo-GSLs with a compensatory increase in $\mathrm{CDH}$, GM3, and neolacto-GSLs (nLc4, snLc4) similar to that observed in the $\mathrm{P}^{\mathrm{k}}$ and p phenotype (Fig. 6). ${ }^{11,25}$ The basis for decreased $\alpha 4$ GALT1 activity is unknown although one obvious possibility is heterozygosity for a null A4GALT1 allele. Family studies in p kindreds, however, have shown normal RBC GSL expression in heterozygous family members. ${ }^{11,25}$ Alternatively, Kundu and colleagues ${ }^{11}$ proposed inheritance of a mutant A4GALT1 allele with functionally decreased enzyme activity. Unfortunately, we were unable to sequence the patient's A4GALT1 gene.

In summary, we report the first case of a clinically significant anti-LKE, capable of binding MSGG, in a male patient with lymphoma. This is the second case of weak $P$ described and is the first associated with an anti-LKE.

\section{CONFLICT OF INTEREST}

The authors have disclosed no conflicts of interest. 


\section{REFERENCES}

1. Kannagi R, Cochran NA, Ishigami F, et al. Stage-specific embryonic antigens (SSEA-3 and -4) are epitopes of a unique globo-series ganglioside isolated from human teratocarcinoma cells. EMBO J 1983;2:2355-61.

2. Tippett $\mathrm{P}$, Andrews $\mathrm{P}$, Knowles BB, et al. Red cell antigens $\mathrm{P}$ (globoside) and Luke: identification by monoclonal antibodies defining the murine stage-specific embryonic antigens -3 and -4 (SSEA-3 and SSEA-4). Vox Sang 1986;51: 53-6.

3. Tippet P. Contributions of monoclonal antibodies to understanding one new and some old blood group systems. Arlington (VA): American Association of Blood Banks; 1986.

4. Cooling L, Kelley K. Inverse expression of $\mathrm{P}^{\mathrm{k}}$ and Luke blood group antigens on human RBCs. Transfusion 2001; 41:898-907.

5. Tippett P, Sanger R, Race RR, et al. An agglutinin associated with the $\mathrm{P}$ and $\mathrm{ABO}$ blood group systems. Vox Sang 1965;10:269-80.

6. Moller B, Jorgensen J. Phenotype frequency of LKE in the Danish population. Hum Hered 1988;38:375-77.

7. Bruce M, Watt A, Gabra GS, et al. LKE red cell antigen and its relationship to $\mathrm{P}_{1}$ and $\mathrm{P}^{\mathrm{k}}$ : serological study of a large family. Vox Sang 1988;33:237-40.

8. Kundu SK, Evans A, Rizvi J, et al. A new $\mathrm{P}^{\mathrm{k}}$ phenotype in the P blood group system. J Immunogenet 1980;7:431-39.

9. Stapleton A, Nudelman E, Clausen H, et al. Binding of uropathogenic E. coli R45 to glycolipids extracted from vaginal epithelial cells is dependent on histo-blood group secretor status. J Clin Invest 1992;90:965-72.

10. Race RR, Sanger R. Blood groups in man. 6th ed. Oxford: Blackwell Scientific Publications; 1965.

11. Kundu SK, Steane SM, Bloom JEC, et al. Abnormal glycolipid composition of erythrocytes with a weak P phenotype. Vox Sang 1978;35:160-7.

12. Roback JD, editor. Technical manual. 17th ed. Bethesda (MD): American Association of Blood Banks; 2011.

13. Judd WJ, Johnson ST, Storry JR, editors. Judd's methods in immunohematology. 3rd ed. Bethseda (MD): American Association of Blood Banks Press; 2008.

14. Kannagi R, Levery SB, Ishigami F, et al. New globoseries glycosphingolipids in human teratocarcinoma reactive with the monoclonal antibody directed to a developmentally regulated antigen, stage-specific embryonic antigen 3. J Biol Chem 1983;258:8934-42.

15. Fenderson BA, Nichols EJ, Clausen H, et al. A monoclonal antibody defining a binary $\mathrm{N}$-acetyl-lactosaminyl structure in lactoisooctaosyl ceramide. Mol Immunol 1986;23:74754.

16. Clegg S. Cloning of genes determining the production of mannose-resistant fimbriae in a uropathogenic strain of Escherichia coli belonging to serogroup O6. Infect Immun 1985;38:739-44.
17. Serum, Cells and Rare Fluids Exchange (SCARF). [cited 2013 Jan 30]. Available from: http://scarfex.jove.prohosting .com/contact.html

18. Cooling L. A new look at an old case: an auto-anti-P with pseudo-LKE activity. Int J Blood Transfus Immunohematol 2013;2:11-21.

19. Marsh WL. Scoring of hemagglutination reactions. Transfusion 1872;12:352-3.

20. Judd WJ, Cooling L. Novel application of the gel test: detection of microbial-induced hemagglutination. Vox Sang 2004;87(S):S17.

21. Ledeen RW, Yu RK. Gangliosides: structure, isolation and analysis. In: Ginsberg V, editor. Methods in enzymology, vol. 83. New York: Academic Press; 1982. p. 139-91.

22. Schnaar RL, Needham LK. Thin layer chromatography of glycosphingolipids. In: Lennarz WJ, Hart GW, editors. Methods in enzymology, vol. 230. New York: Academic Press; 1994. p. 371-89.

23. Cooling LLW, Zhang D-S, Naides SJ, et al. Glycosphingolipid expression in acute nonlymphocytic leukemia: common expression of shiga toxin and parvovirus B19 receptors on early myeloblasts. Blood 2003; 101:711-21.

24. Cooling LL, Zhang DS, Walker KW, et al. Detection in human blood platelets of sialyl Lewis X gangliosides: potential ligands for CD62 and other selectins. Glycobiology 1995;5:571-81.

25. Kundu SK, Suzuki A, Sabo B, et al. Erythrocyte glycosphingolipids of four siblings with the rare blood group p phenotype and their parents. J Immunogenet 1981;8:357-65.

26. Yiu SCK, Lingwood CA. Polyisobutylmethacrylate modifies glycolipid binding specificity of verotoxin 1 in thin-layer chromatogram overlay procedures. Anal Biochem 1992; 202:188-92.

27. Gallegos KM, Conrady DG, Karve SS, et al. Shiga toxin binding to glycolipids and glycans. Plos ONE 2012;7: e30368-10.

28. Flechter KS, Bremer IG, Schwarting GA. P blood group regulation of glycosphingolipid levels in human erythrocytes. J Biol Chem 1979;254:11196-8.

29. Bierbach E, Yu RK. Multi-enzyme kinetic analysis of glycolipid biosynthesis. Biochim Biophys Acta 1999;1432:113-24.

30. Kannagi R, Papyannopoulou T, Nakamoto B, et al. Carbohydrate antigen profiles of human erythroleukemia cell lines HEL and K562. Blood 1983;62:1230-41.

31. Watanabe K, Powell ME, Hakomori S-I. Isolation and characterization of gangliosides with a new sialosyl linkage and core structures. J Biol Chem 1979;254:8223-9.

32. Muthing J, Spanbroek R, Peter-Katalinic J, et al. Isolation and structural characterization of fucosylated gangliosides with linear poly-N-acetyllactosaminyl chains from human granulocytes. Glycobiology 1996;6:147-56.

33. Katagiri YU, Ohmi K, Katagiri C, et al. Prominent immunogenicity of monosialosyl galactosylgloboside, carrying a 
stage-specific embryonic antigen-4 (SSEA-4) epitope in the ACHN human renal tubular cell line-a simple method for producing monoclonal antibodies against detergentinsoluble microdomains/raft. Glyconj J 2001;18:347-53.

34. Cooling L, Hwang D. Monoclonal antibody B2, a marker of neuroendocrine sympathoadrenal precursors, recognizes the Luke (LKE) antigen. Transfusion 2005;45:709-16.

35. Stapleton AE, Stroud MR, Hakomori S, et al. The globoseries glycosphingolipid sialosyl galactosyl globoside is found in urinary tract tissues and is a preferred receptor in vitro for uropathogenic Escherichia coli expressing papencoded adhesions. Infect Immun 1998;66:3856-61.

36. Karr JF, Nowicki BJ, Truong DL, et al. Pap-2-encoded fimbriae adhere to the $\mathrm{P}$ blood group-related glycosphingolipid stage-specific embryonic antigen 4 in the human kidney. Infect Immun 1990;58:4055-62.

37. Ito A, Saito S, Masuko T, et al. Monoclonal antibody (5F3) defining renal cell carcinoma-associated antigen disialosyl globopentaosylceramide (V3NeuAcIV6NeuAcGb5), and distribution pattern of the antigen in tumor and normal tissues. Glyconj J 2001;18:475-85.

38. Saito S, Levery SB, Salyan MEK, et al. Common tetrasaccharide epitope NeuAc $\alpha 2-3 \mathrm{Gal} \beta 1-3$ (NeuAc $\alpha 2-6)$ GalNAc, presented by different carrier glycosylceramides or O-linked peptides, is recognized by different antibodies and ligands having distinct specificities. J Biol Chem 1994; 269:5644-52.

39. Stroud MR, Stapleton AE, Levery SB. The P histo-blood group-related glycosphingolipid sialosyl galactosyl globoside as a preferred binding receptor for uropathogenic Escherichia coli: isolation and structural characterization from human kidney. Biochemistry 1998; 37:17420-8.

40. Gillard BK, Jones MA, Marcus DM. Glycosphingolipids of human umbilical vein endothelial cells and smooth muscle cells. Arch Biochem Biophys 1987;256:435-45.

41. Cooling LL, Zhang D, Koerner TA. Human platelets express gangliosides with LKE activity and $\mathrm{ABH}$ blood group activity. Transfusion 2001;41:504-16.

42. Steelant WF, Kawakami Y, Ito A, et al. Monosialyl-Gb5 organized with cSrc and FAK in GEM of human breast carcinoma MCF-7 cells defines their invasive properties. FEBS Lett 2002;531:93-8.

43. Draper JS, Pigott C, Thomson JA, et al. Surface antigens of human embryonic stem cells: changes upon differentiation in culture. J Anat 2002;200:249-58.

44. Lawrie CH, Marafioti T, Hatton CSR, et al. Cancerassociated carbohydrate identification in Hodgkin's lymphoma by carbohydrate array profiling. Int J Cancer 2006; 118:3161-66.

45. Kalisiak A, Minniti JG, Oosterwijk E, et al. Neutral glycosphingolipid expression in B-cell neoplasm. Int J Cancer 1991;49:837-45.

46. O'Boyle KP, Freeman K, Kalisiak A, et al. Patterns of ganglioside expression in B cell cell neoplasms. Leuk Lymphoma 1996;21:255-66.

47. Meyer zum Buschenfelde C, Feuerstacke Y, Gotze KS, et al GM1 expression of non-Hodgkin's lymphoma determines susceptibility to rituximab treatment. Cancer Res 2008;68: 5414-22.

48. Noguchi R, Shinomiya N, Nagai K, et al. Induction of suppressor $\mathrm{T}$ cells by anti-globoside antibodies in cancer sera. Jpn J Clin Oncol 1983;13:335-42.

49. Smorodin EP, Kurtenkov OA, Sergeyev BL, et al. The relation of serum anti-( $\beta$ GalNAc) and para-Forssman disaccharide IgG levels to the progression and histological grading of gastrointestinal cancer. Exp Oncol 2007;29:61-6.

50. Wang C-C, Huang Y-L, Ren C-T, et al. Glycan microarray of globo-H and related structures for quantitative analysis of breast cancer. Proc Natl Acad Sci U S A 2008;105:11661-66.

51. Schrump DS, Furukawa K, Yamaguchi H, et al. Recognition of galactosylgloboside derived from patients with primary lung cancer. Proc Natl Acad Sci U S A 1988;85:4441-5.

52. Jacob F, Goldstein DR, Bovin NV, et al. Serum antiglycan antibody detection of nonmucinous ovarian cancers by using a printed glycan array. Int J Cancer 2011;130: 138-46.

53. Hansson GC, Wazniowska K, Rock JA, et al. The glycosphingolipid composition of the placenta of a blood group $\mathrm{P}$ fetus deliverd by a blood group $\mathrm{P}_{1}{ }^{\mathrm{k}}$ woman and analysis of the anti-globoside antibodies in maternal serum. Arch Biochem Biophys 1988;260:168-76. 